\title{
Seasonal evolution of the West African heat low: a climatological perspective
}

\author{
C. Lavaysse $\cdot$ C. Flamant $\cdot$ S. Janicot $\cdot$ D. J. Parker $\cdot$ \\ J.-P. Lafore $\cdot$ B. Sultan $\cdot$ J. Pelon
}

Received: 22 February 2008/Accepted: 11 March 2009/Published online: 12 April 2009

(c) The Author(s) 2009. This article is published with open access at Springerlink.com

\begin{abstract}
The West African heat low (WAHL), a region of high surface temperatures and low surface pressures, is a key element of the West African monsoon system. In this study, we propose a method to detect the WAHL in order to monitor its climatological seasonal displacement over West Africa during the period 1979-2001, using the European Centre for Medium-range Weather Forecast (ECMWF) ERA-40 reanalyses. The low-level atmospheric thickness (LLAT), a variable defined as the difference of geopotential heights at 700 and $925 \mathrm{hPa}$, is used to detect the dilatation of these levels generated by an increase of the temperature. We define grid points with $10 \%$ highest values of the LLAT as the WAHL. We show that our method reliably positions the WAHL over areas of high surface temperatures and low surface pressures, and that it is effective at detecting heat lows. In the course of the year, the climatological WAHL is shown to migrate northwestward from a position south of the Darfur mountains in the winter (November-March) to a location over the Sahara, between the Hoggar and the Atlas mountains, during the summer (June-September). The temperature tendency equation is used to investigate the processes controlling the displacement of the WAHL, and more
\end{abstract}

C. Lavaysse $(\bowtie) \cdot$ C. Flamant $\cdot$ J. Pelon

Service d'Aéronomie, Paris, France

e-mail: christophe.lavaysse@aero.jussieu.fr

S. Janicot $\cdot$ B. Sultan

LOCEAN, Paris, France

D. J. Parker

University of Leeds, Leeds, UK

J.-P. Lafore

CNRM-Meteo France, Toulouse, France particularly the heating at low levels. The specific period of the onset of the WAHL in its summer location over the Sahara (referred to as the Saharan heat low -SHL- onset) is also analysed during the 1984-2001 period, using complementary brightness temperature data from the European Union-funded Cloud Archive User Service (CLAUS). The climatological onset of the SHL occurs around 20 June, i.e. just before the climatological monsoon onset date. The present study suggests that the onset of the WAHL occurs approximately 5 days before the monsoon onset for the 1984-2001 period. This is confirmed independently by comparing the SHL onset date and the monsoon onset date for the 1984-2001 period. The seasonal evolution of the WAHL for the year 2006 (the year of the African Monsoon Multidisciplinary Analysis project Special Observation Period) is analysed and compared with the climatological results. The operational ECMWF analyses were used for that purpose. Except in April, the spatial distribution of the WAHL remains relatively unchanged and agrees with the climatology. The onset of the SHL in 2006 occurs on 18 June, which is close to the climatological date, in spite of the delay in the onset of the rainy season in Sahel.

Keywords West Africa - Heat low - Monsoon · Climate $\cdot$ Low level circulation - Geopotential height

\section{Introduction}

Over continental West Africa, an area of high surface temperatures and low surface pressures (i.e. a heat low) exists throughout the year and occurs where insolation is high and evaporation is low.

In the summer, the West African heat low (WAHL) is generally positioned over the Sahara and is often referred 
to as the Saharan heat low. During this period, the WAHL is considered to be a major dynamical element of the West African Monsoon system, together with the African Easterly Jet (AEJ, Thorncroft and Blackburn 1999), the Tropical Easterly Jet and African Easterly Waves (AEWs, Diedhiou et al. 1998; Thorncroft and Hodges 2001; Fink and Reiner 2003; Lavaysse et al. 2006).

In the lower troposphere, the cyclonic circulation associated with the WAHL tends to increase both the southwesterly monsoon flow along its eastern flank and the north-easterly Harmattan flow along its western flank (Parker et al. 2005b). Moreover, the WAHL has a large impact on the structure and dynamics of the AEJ. The upward motion in the WAHL generates an anticyclonic circulation aloft (around $700 \mathrm{hPa}$ ) which contributes to strengthen the AEJ. Thorncroft and Blackburn (1999) have shown that the combination of the diabatically forced meridional circulation associated with the surfaces fluxes and dry convection in the WAHL is crucial to maintain the AEJ. The specific impact of the heat low appears to be associated with the dome-shaped heating feature in the lower troposphere and the two resulting meridional circulations along the fringes of the temperature anomaly. At $700 \mathrm{hPa}$ the equatorward branch of this circulation results in an acceleration of the AEJ through the conservation of the angular momentum (see Fig. 8 in Thorncroft and Blackburn 1999).

Nevertheless, our knowledge of the WAHL impact on the West African monsoon system is still limited. For instance several studies have pointed out the likely role of the WAHL on the so-called monsoon onset (e.g. Sultan and Janicot 2003; Ramel et al. 2006; Sijikumar et al. 2006) and the suggested mechanisms linking the WAHL with the onset are quite different in these studies.

Using a composite study based on the National Centers for Environmental Prediction (NCEP) re-analyses, Sultan and Janicot (2003) suggested that the Atlas and Hoggar mountains are likely to play an important role in the mechanism leading to the abrupt shift of the inter-tropical convergence zone (ITCZ, defined as the convective rain belt)), by enhancing the WAHL cyclonic circulation in the low levels. Subsidence over and north of these orographic features, associated with the northern branches of the meridional circulation of both the WAHL and the Hadley cell, contributes to enhance the high geopotential north of these mountains and the associated north-easterly winds. This leads to the development of a leeward trough that maintains an active convective ITCZ through enhanced moist air advection from the ocean, with a strong meridional circulation. Using a linear model, Drobinski et al. (2005) have shown that, during the monsoon onset period, the increase of the pressure gradient north of the Hoggar resulted in an increase of the windward flow speed, as well as a rotation of the wind direction from south-easterly to north-easterly in that region. This evolution tends to increase the leeward depression to the south-west of the Hoggar and enhances the cyclonic circulation associated with the WAHL.

These suggestions have been re-examined by Ramel et al. (2006) using the Regional Climate Model MAR (Galle et al. 2004). Focusing on the year 1992, they observed two preferred positions of the WAHL during the summer; first over the Sahel $\left(10-15^{\circ} \mathrm{N}\right)$, before the monsoon onset period, and then over the Sahara $\left(20-25^{\circ} \mathrm{N}\right)$ during the rainy season in Sahel. They found the WAHL transition from one position to the other to be linked to the northward propagation of the surface temperature maximum as a result of favourable surface albedo and solar heating conditions. They suggest the monsoon onset occurring at the end of June to be associated with the shift of the WAHL from its Sahelian position to its Saharan position.

Most studies have focused on specific processes affecting the WAHL, using idealized approaches (Chou et al. 2001; Drobinski et al. 2005; Peyrille and Lafore 2007) or regional numerical simulations, and sometimes on a given, possibly non representative year (e.g. Ramel et al. 2006). Improved understanding of the impact of the WAHL on the West African monsoon system will only be achieved through an analysis of the role of all processes acting to influence the seasonal life cycle of the WAHL. In this context, the definition of a robust, objective method to detect the WAHL that can be used to diagnose this feature in climate models or in mesoscale models is of great importance.

In the framework of the AMMA project (Redelsperger et al. 2006), the importance of the SHL (and adjacent ITD) has long been recognised. As a result, an ambitious experimental strategy which involved balanced contributions from ground-based and airborne platforms was designed as part of the AMMA Special Observing Periods (SOPs) that took place in the summer of 2006. In particular, aircraft-oriented 'ITD and SHL surveys' have been designed with the objective to improve knowledge of the PBL dynamics and thermodynamics in the ITD region and along the southern fringes of the SHL. Daily maps of WAHL occurrence frequency and depths (not shown) will be valuable for the interpretation of the data acquired in the framework of the airborne missions.

This paper aims to use 23 years of the European Centre for Medium-range Weather Forecasts (ECMWF) ERA-40 re-analysis data (Uppala et al. 2005) and complementary datasets to: (1) propose an objective method to detect the WAHL, (2) provide an overview of the climatological seasonal evolution of the WAHL using this method, and (3) investigate the link between the climatological seasonal dynamics of the WAHL and the West African monsoon. 
The paper is organized as follows. The dataset used in this study is presented in Sect. 2. We detail the WAHL detection method in Sect. 3. In Sect. 4, the seasonal evolution of the climatological WAHL location is presented and the link with low-level temperature and pressure is discussed. We also elaborate on the diurnal cycle of the WAHL in the summer. In Sect. 5, we investigate the link between the climatological seasonal dynamics of the WAHL and the West African monsoon. The seasonal cycle of the WAHL for the year 2006 (i.e. the year of the African monsoon multidisciplinary analysis (AMMA) special observation period (SOP) (Redelsperger et al. 2006) is discussed with respect to the climatology in Sect. 6. Then, we summarize and conclude in Sect. 7.

\section{Dataset}

In this study, only the satellite period of the ECMWF ERA40 re-analysis data, i.e. from 1979 to 2001, has been used. It is generally regarded as the more reliable part of the dataset for climatological analysis (Kallberg et al. 2005). The model variables are available on 23 pressure levels between 1,000 and $1 \mathrm{hPa}$, with a horizontal resolution of $1.125^{\circ} \times 1.125^{\circ}$. The following fields have been used in this study: the three components of the wind as well as temperature and the skin temperature. The planetary boundary layer (PBL) depth (provided by the ERA-40 forecasts, not re-analyses) was also used.

To date there exist very few observational datasets to evaluate the model-based climatological studies. In this study, we have used brightness temperature data from the European Union-funded Cloud Archive User Service $\left(\mathrm{CLAUS}^{1}\right)$ to look into climatological patterns of nearsurface temperatures as well as convection. The CLAUS project maintains a long time-series of three-hourly global window channel thermal infra-red images of the Earth based on the level B3 $10 \mu \mathrm{m}$ radiances from operational meteorological satellites participating in the International Satellite Cloud Climatology Programme (ISCCP, Brest et al. 1997). The CLAUS archive currently spans the period 1984-2004. In this work, the infra-red brightness temperature fields have been interpolated onto a regular horizontal grid at the spatial resolution of $0.5^{\circ} \times 0.5^{\circ}$. Daily brightness temperatures (obtained by averaging data from 3-hourly CLAUS data) were used to avoid biases linked with the diurnal cycle of convection and solar radiation. Brightness temperatures below $270 \mathrm{~K}$ which are generally associated with the top of deep convective clouds, were used to build a climatology of deep convection occurrence frequency over the area of interest.

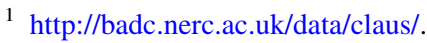

Likewise, brightness temperatures above $300 \mathrm{~K}$ which are linked to surface radiance and low-level atmospheric temperature in cloud free conditions, were used to monitor the climatological behaviour of temperature in the lower troposphere.

\section{WAHL detection method}

\subsection{Background}

Figure 1 shows the domain over which the WAHL detection has been applied. The quasi-zonal homogeneity of the land cover over West Africa allows us to study the seasonal cycle of the West African monsoon system as a function of latitude between $15^{\circ} \mathrm{W}$ to $10^{\circ} \mathrm{E}$, on average, as in many previous studies.

A heat low is an area of low atmospheric pressure near the surface resulting from heating of the lower troposphere and the subsequent lifting of isobaric surfaces and divergence of air aloft. As noted by Knippertz and Fink (2008), the WAHL often takes the form of a zonally elongated heat trough rather than a circular low, depending on the season. It also exhibits a distinct characteristic vertical structure as now described (also see RA99).

The typical daily variations of heat low circulations has been highlighted by Racz and Smith (1999) (RA99 hereafter) based on idealised numerical simulations, and confirmed for the West African region by Parker et al. (2005a). Minimum surface pressure and hottest temperatures associated with heat lows occur during the afternoon, when the PBL is deep and well mixed, and when high eddy viscosity leads to weak winds. On the other hand, the

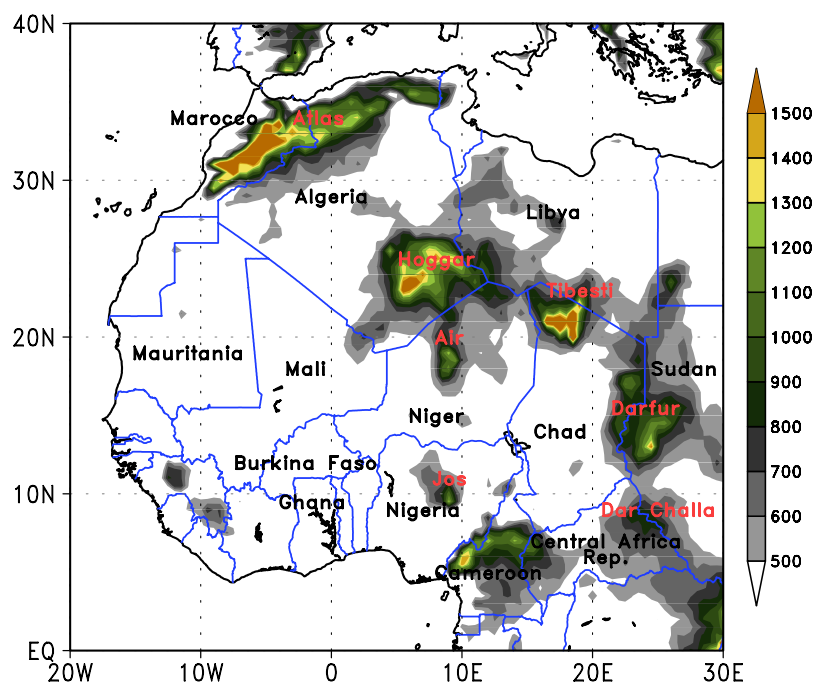

Fig. 1 Topography over West Africa. The names of the countries (mountains) are indicated in black (blue) 
temperature minimum and the pressure maximum are reached in the heat low region shortly before sunrise. Around this time, low-level jets (LLJs) are strongest above the surface inversion and directed towards the pressure minimum which corresponds to the heat low area (in the absence of extra-tropical forcing, the pressure minimum in the heat low region seen at 0600 UTC in the re-analyses generally coincides with the lowest pressures over the continent).

In this study, the WAHL characteristics have been retrieved using 0600 UTC re-analysis fields only, at a time when: (1) low-level winds associated with the heat low are strongest; (2) the perturbation in the low-level temperature field induced by the presence of clouds is minimal (the occurrence of convective clouds developing in the afternoon will impact the radiative budget in the lower troposphere); and (3) the perturbation in the low-level temperature field induced by complex surface albedo patterns is minimal.

In the lower layers (around $925 \mathrm{hPa}$ ), the WAHL is characterized by a negative anomaly of geopotential associated with an increase of the potential temperature (Fig. 2). These characteristics are observed both in the winter (around $12^{\circ} \mathrm{N}$, Fig. 2a) and in the summer (around $21^{\circ} \mathrm{N}$, Fig. 2b). The strongest ascent in the region of the WAHL is seen between the surface and $700 \mathrm{hPa}$ (on average) along its southern edge. This ascent is associated with the meridional circulation developing along the southern fringes of the WAHL, in response to the heating in the low levels, as well as lower tropospheric convergence between the south-westerly monsoon and the northeasterly Harmattan, the near-surface position of this convergence zone being referred to as the Inter-Tropical discontinuity (ITD). Above $600 \mathrm{hPa}$, strong subsiding motion connected to the subsiding branch of the Hadley cell are seen to cap the strongest ascent associated with the WAHL, both on the winter and in the summer (Fig. 2a, b, respectively). A distinct region of easterly winds is seen at the level of this elevated convergence and south of the WAHL (Fig. 2a). This easterly flow is associated with the reinforcement of the meridional circulation south of the WAHL in the summer, in agreement with Thorncroft and Blackburn (1999).

\subsection{Local detection criterion}

The objective heat low detection criterion needs to account for key features of the atmospheric dynamics and thermodynamics associated with the WAHL, particularly in the vertical. Furthermore, it is critical that the criterion detects the low pressure associated with the heating in the low levels, and not that resulting by extra-tropical forcing, such as mid-latitude depressions.

We propose a criterion based on the heat-induced dilatation of the low levels to identify the presence of the WAHL. To do so, we estimate the low-level atmospheric
Fig. 2 Mean latitudinal crosssection of potential temperature ( $\mathrm{K}$, black solid lines), zonal wind (dashed lines, 8 and $10 \mathrm{~m} \mathrm{~s}^{-1}$ contours) and anomaly of geopotential height with respect to the average at each pressure level (in $\mathrm{m}$, contours) for the JanuaryMarch period (a) and for the July-September period (b). Vectors show the wind along the cross-section (both vertical, in $\mathrm{Pa} \mathrm{s}^{-1}$, and meridional, in $\mathrm{m} \mathrm{s}^{-1}$, components). Variables in the cross-section are averaged from $15^{\circ} \mathrm{W}$ to $10^{\circ} \mathrm{E}$ and for the 23 years of the ERA-40 re-analysis used in this study (a)

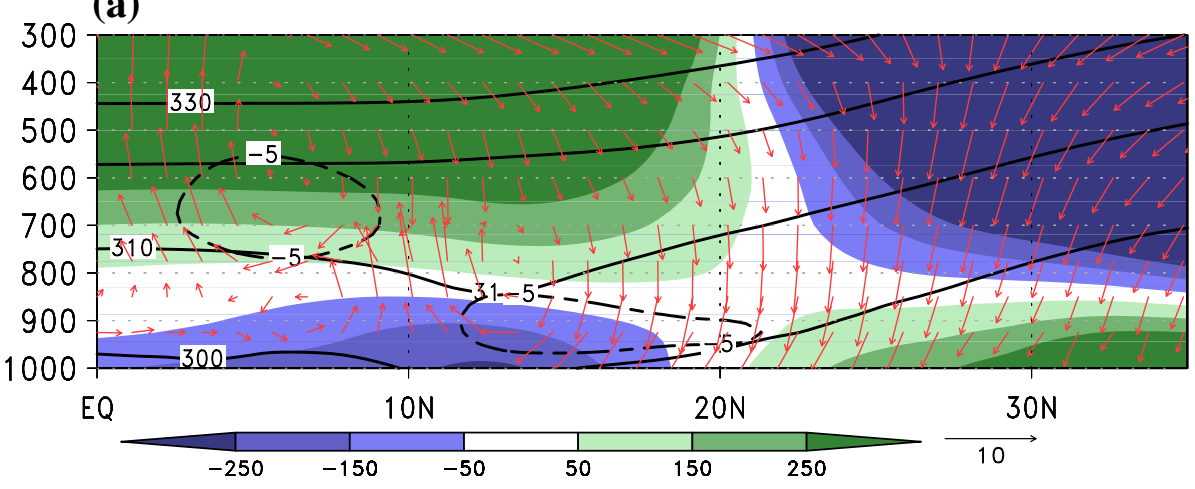

(b)

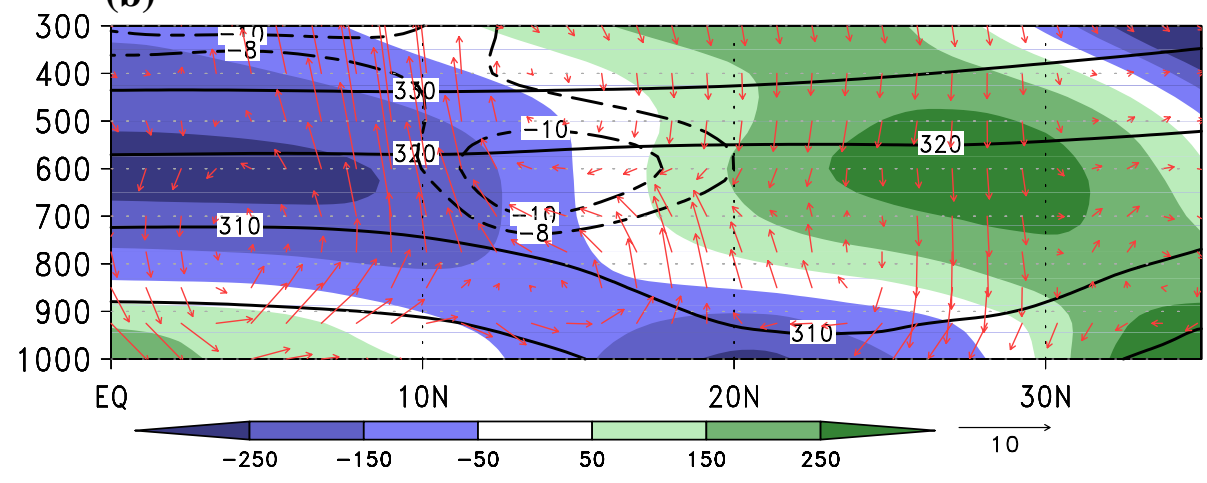


thickness (LLAT) between two pressure levels of the re-analyses. The upper-level boundary is chosen as $700 \mathrm{hPa}$ (around 3,500 $\mathrm{m}$ above mean sea level -msl- on average over West Africa) based on the discussion above. This also prevents spurious detection of geopotential anomalies in the upper atmosphere due to mid level circulations. The lower boundary is selected as $925 \mathrm{hPa}$.

The so-defined LLAT is related to the mean temperature of the layer by:

$\Delta Z=\frac{R}{g} \int_{p 2}^{p 1} T d(\ln (p))$,

where $(\Delta Z)$ is the LLAT, $R$ is the gas constant for air, $g$ is gravitational acceleration, $T$ is temperature and $p$ is pressure. $p_{2}$ and $p_{1}$ correspond to 925 and $700 \mathrm{hPa}$. Hence, this ensures that the LLAT criterion accounts for the heatinduced dilatation of the atmospheric column. For the entire ERA-40 dataset, the spatial correlation between the potential temperature at 925,850 and $700 \mathrm{hPa}$ and LLAT (computed over the whole of the domain shown in Fig. 1) is equal to $0.96,0.98$ and 0.96 , respectively. In Sect. 4.3, we will show that this criterion also enables us to screen out the surface pressure perturbations associated with midlatitude depressions, and that the LLAT-derived WAHL position indeed corresponds to a region of low surface pressure.

\subsection{Application of the criterion to the whole of West Africa}

On a given day, the WAHL is defined as the area over West Africa and Atlantic (see Fig. 1) where the LLAT which characterizes the depth of the WAHL exceeds a given (arbitrarily set) threshold. We chose to work on a daily basis, essentially due to the strong seasonal evolution of the LLAT. The method using an independent daily threshold from 1 year to another allows us to analyse the inter-annual and the intra-seasonal variability of the LLAT. This threshold is defined as the $90 \%$ level of the daily cumulative probability distribution function of LLAT computed over the West African domain. Using this value, it may happen (particularly during the winter) that several distinct regions are identified as qualifying as heat low regions. In all cases, there always is an area that stands out as being wider and deeper. The detected 'secondary areas' are generally found to be close to the ITD. In the following no screening is applied, and we account for all detected areas with LLATs larger than the threshold.

Figure 3 illustrates the seasonal evolution of the average threshold over 23 years, as well as its standard deviation. An indication of the daily threshold minimum and maximum values over the 23 year period is also shown. The

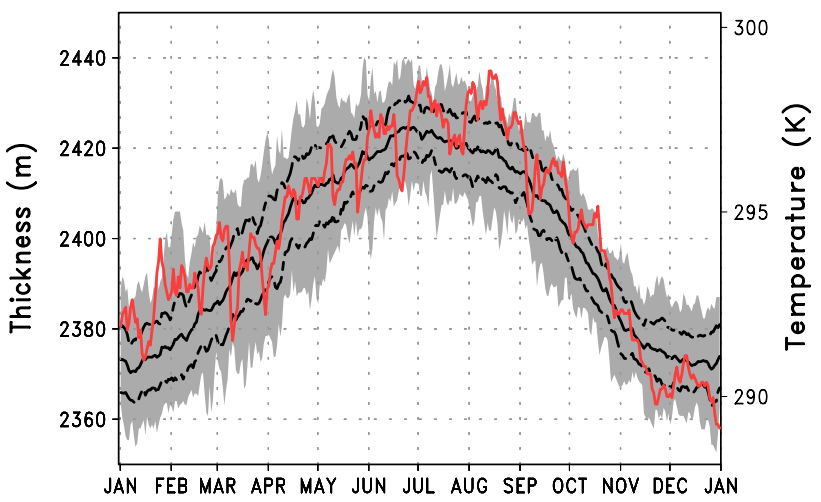

Fig. 3 Mean LLAT thickness threshold (m) derived from 23 years of ERA-40 re-analysis (black line) and standard deviation (dotted lines). Grey shading represents the daily minimum and maximum values in the 23 year period. The red line represents the LLAT thickness threshold for 2006. The right $y$-axis indicates the equivalent temperature at $850 \mathrm{hPa}$ obtained using the hydrostatic equation $(\mathrm{K})$

mean threshold exhibits a seasonal evolution, from 2,370 to $2,425 \mathrm{~m}$, with a maximum at the end of June and the beginning of July. This corresponds to an increase in temperature in the considered atmospheric layer between 291 and $297.5 \mathrm{~K}$, using Eq. (1). This evolution may partly be due to the increase, with latitude, of the fraction of land from $15 \mathrm{~W}$ to $10 \mathrm{E}$ in the domain which is beneath the solar zenith. Moreover, the increase of the threshold also suggests an impact of surface properties (albedo, vegetation) or dust plumes which may generate an increase of atmospheric temperature, and thus thickness, over the Sahara. The average threshold exhibits an increase phase (from February-June) which is slower than the decrease phase (September-November). It has to be acknowledged that part of the strong seasonal signal is likely to be due to the fact that we are only considering a domain located in the northern hemisphere and thus with an increase of the solar radiation during the summer season.

The sensitivity of the WAHL detection to the value of the threshold has also been investigated. When using a threshold defined as $80 \%$ of the cumulative probability distribution, the domain covered by the WAHL appears too wide and to cover the whole of the Sahara. Moreover, there is hardly any seasonal evolution of the WAHL, especially during the spring and fall periods. A more stringent value of the cumulative distribution (i.e. 95\%) enables us to detect well-defined heat low areas. However, they are more numerous and exhibit a large spatial variability from 1 day to the other which makes it more difficult to analyse the seasonal evolution of the WAHL in a consistent way due to the larger fragmentation. Thus, a threshold based on a value of $90 \%$ of the cumulative probability distribution appears to be a reasonable compromise for WAHL detection. In the following, we have used this value. 
In summary, the WAHL detection algorithm runs in three steps on a given day of a given year: (1) The LLAT is calculated between 925 and $700 \mathrm{hPa}$ from the 0600 UTC geopotential field; (2) A cumulative probability distribution function of the LLATs is computed on all of the 1,702 grid points of the domain extending over West Africa and adjacent Tropical Atlantic, i.e. between $20^{\circ} \mathrm{W}$ and $30^{\circ} \mathrm{E}$, and between $0^{\circ} \mathrm{N}$ and $40^{\circ} \mathrm{N}$; (3) The WAHL is defined as the area where the LLAT exceeds a threshold defined as $90 \%$ of the LLAT cumulative probability distribution function (i.e. the highest $10 \%$ values of LLAT). A relative (i.e. daily) threshold rather than an absolute threshold is used because, on a given day, the WAHL can be defined as depression relative to its environment. Due to the large seasonal cycle of the LLAT over West Africa, but also to its inter-annual variability, the use of an absolute threshold (based on a seasonal or annual average) will introduce biases in the LLAT statistics built from the 35 years of the ERA-40 archive used in this study.

\section{Climatological analysis of the WAHL}

In this section, we first describe the seasonal evolution of WAHL. We then investigate the origin of the temperature increase in the low levels associated with the WAHL discussed in Sect. 3 using a temperature tendency equation. We then present evidence of the link between the location of the WAHL as detected in the present analysis and the location of the lowest surface pressure over the continent. Finally, the climatological diurnal cycle of the WAHL during the summer is presented.

\subsection{WAHL seasonal evolution}

Figure 4 shows the climatological, monthly-averaged location of the WAHL from January to December. The shaded contours indicate the occurrence frequency of the WAHL for each grid point. The $925 \mathrm{hPa}$ wind field is overlain (grey vectors) to illustrate the lower tropospheric circulation. Areas of strong wind convergence (larger than $8 \times 10^{-6} \mathrm{~s}^{-1}$ ) are indicated as blue contours). Note that the convergence may also result from the interaction of the orography with the mean flow, and that strong convergence is generally found along the windward edge of the mountains (eastern side of the Atlas or southern side of the Hoggar in August, for example). The position of the ITD is usually determined by meteorologists from surface dewpoint temperature and wind direction measurements (e.g. Buckle 1996; Lafore et al. 2007). Buckle (1996) defines the ITD using the $14^{\circ} \mathrm{C}$ dew-point temperature criterion, with air to the north (south) of the ITD being characterized by dew-point temperatures less than (in excess of) $14^{\circ} \mathrm{C}$ and northerly to easterly (southerly to westerly) winds. In the framework of the AMMA project, the forecasters used three criteria to provide daily forecasts of the ITD position at 0600 UTC: near surface convergence, a dew-point temperature of $15^{\circ} \mathrm{C}$ and pressure which should exhibit a local minimum at the ITD (Lafore et al. 2007). In this paper, we show the location of the ITD determined from the location of the minimum geopotential height which allows us to locate the minimum of pressure.

In January and February, the distribution patterns of the WAHL occurrence frequency are quite similar (Fig. 4a, b). The maximum of occurrence frequency is centred over the eastern Central African Republic $\left(8^{\circ} \mathrm{N}, 20^{\circ} \mathrm{E}\right)$ in the southwestern edge of the Darfur mountains (Sudan) and the Dar Challa mountains (Central African Republic, around $9^{\circ} \mathrm{N}$, $\left.20^{\circ} \mathrm{E}\right)$. There also exists a large, zonally oriented region (centred around $10^{\circ} \mathrm{N}$, between $15^{\circ} \mathrm{W}$ and $25^{\circ} \mathrm{E}$ ), north of the ITD, where the WAHL occurrence frequency is in excess of $20 \%$. Hence, in this case, the WAHL takes the form of a circular low over the Central African Republic, while taking the form of an elongated heat trough over the Sudanian region (an area comprised from $10 \mathrm{~W}$ to $10 \mathrm{E}$, and between $7.5 \mathrm{~N}$ and $10 \mathrm{~N}$ ).

In March, there is a slight northward progression of the elongated heat trough (Fig. 4c) which is linked to the northward migration of the solar radiation. Strong northeasterly winds in the lee of the constriction between the Tibesti and the Darfur seems to stop the progression of the circular low in the lee of the Darfur mountains.

In April and May, the core of the WAHL moves northwestward and is now located south of the Airr, very close to the leeward depression of the Air mountains (Fig. 4d, e). The Harmattan flow over the Sahel is weak, the winds being less than $6 \mathrm{~m} \mathrm{~s}^{-1}$, and the monsoon flow has progressed inland significantly (associated wind speeds being greater than $6 \mathrm{~m} \mathrm{~s}^{-1}$ between $6^{\circ} \mathrm{W}$ and $10^{\circ} \mathrm{E}$ ). The maximum of convergence in the low levels is located south of the Air (around $15^{\circ} \mathrm{N}$ ). In May, a more marked inland progression of the monsoon flow is seen over central West Africa. The monsoon flow appears to spiral around the eastern flank of the WAHL which is now nearly circular in form. During this period, the northward progression of the WAHL is imposed by the northward progression of the solar radiation maximum. The reasons for the westward progression are more complex and could be associated with the leeward depression of the Air and Hoggar mountains, in the southern flank of these mountains, which generates a negative geopotential anomaly (e.g. Drobinski et al. 2007; Semazzi and Sun 1997).

The zonal extension of the WAHL decreases in June, as seen in Fig. 4f. The WAHL occurrence frequency emphasizes that it now is circular in form and that its centre is positioned to the south-west of the Hoggar. Along the 

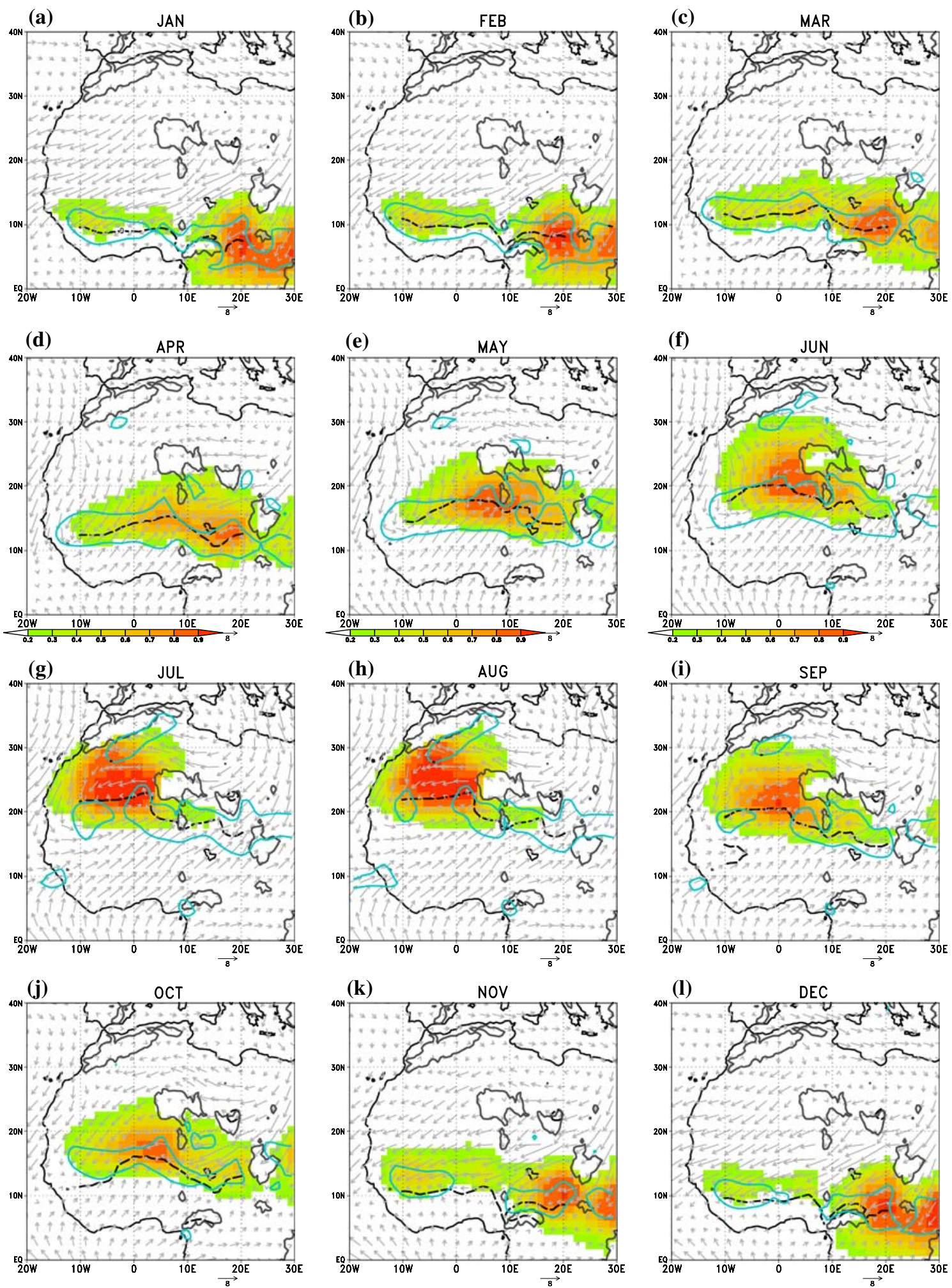

Fig. 4 Monthly mean occurrence frequency of the WAHL (color) and $925 \mathrm{hPa}$ wind field (vectors, $\mathrm{m} \mathrm{s}^{-1}$ ). Blue contours indicate the $8 \times 10^{-6} \mathrm{~s}^{-1}$ level of horizontal convergence and black lines display the position of the lowest $925 \mathrm{hPa}$ geopotential height between the Equator and $28^{\circ} \mathrm{N}$ (an indication of the ITD position). Grey lines display the contour of orography above $925 \mathrm{hPa}$ 
south-eastern edge of the WAHL, the monsoon flow is stronger than in May. The flow splitting along the northern edge of the Hoggar intensifies, thereby creating conditions favourable for the occurrence of a strong easterly Harmattan flow north of the Hoggar and convergence on the windward edge of the Atlas chain.

The core of the WAHL (as derived from its occurrence frequency) progresses north-westward between June and July and remains quasi-stationary during July and August, between the Hoggar and the Atlas, centred roughly at $22^{\circ} \mathrm{N}$ and $2^{\circ} \mathrm{W}$ (Fig. $4 \mathrm{~g}$, h, respectively). This quasi-stationary location over the Sahara is reminiscent of the WAHL location described in previous papers such as Ramel et al. (2006). During this period the most intense cyclonic circulation occurs while the WAHL is positioned in the area free of orography. The region of convergence along the ITD now exhibits two distinct maxima, one occurring downstream of the Hoggar, and the other occurring over Mali and Mauritania. The ITD is quasi-stationary during the months of July and August, and reaches its northernmost location (i.e. $22^{\circ} \mathrm{N}$ ) between $10^{\circ} \mathrm{W}$ and $4^{\circ} \mathrm{E}$. Also, the ITCZ reaches its northernmost position (not shown) and the monsoon flow is strongest. The monsoon flow intensity begins to decrease at the end of August (not shown), and is less than $6 \mathrm{~m} \mathrm{~s}^{-1}$, on average, over the Sahel in September.

In September, the WAHL returns to the same position as in June (Fig. 4i), as a result of the southward movement of the solar zenith position. Nevertheless, as the solar zenith position is at the Equator in September, it appears that the position of the WAHL lags that of the solar zenith position by a few months. This implies some inertia in the system, likely caused by complex surface-atmosphere interactions that are beyond the scope of this paper. The ITD remains very close to the WAHL, but the convergence intensity decreases, in association with the decrease of the monsoon flow intensity.

Between October and November, a rapid southward displacement of the core of the WAHL (where the WAHL occurrence frequency is in excess of 70\%) takes place between a position south-west of the Air and a position mirroring that seen in March, i.e. south-west of Darfur (Fig. 4j, k). A significant southward displacement of the ITD is also seen which is related to the reinforcement of the Harmattan flow in the lee of the constriction between the Hoggar and Tibesti mountains. In November, the position of the WAHL and the associated lower tropospheric cyclonic circulation tends to increase the Harmattan flow along the north-western edge of the WAHL, while in October the cyclonic circulation to the south-east of the WAHL tends to oppose the flow between the Hoggar and Tibesti mountains. In November also, the WAHL over the Sudanian region (where the WAHL occurrence frequency is in excess of 20\%) takes the form of a elongated heat trough as in March. Finally, in December, the WAHL position is close to that seen in January (Fig. 41)

\subsection{Temperature tendency in the lower troposphere}

The climatological time-latitude Hovmoeller diagram of the CLAUS-derived brightness temperature larger than $300 \mathrm{~K}$, together with the percentage of pixels affected by brightness temperature larger then $300 \mathrm{~K}$ averaged between $15^{\circ} \mathrm{W}$ and $10^{\circ} \mathrm{E}$ (Fig. 5), is used to monitor the mean seasonal cycle of surface temperature over West Africa.

During the winter season, the highest brightness temperatures (but still relatively cold-less than $302 \mathrm{~K}$-with respect to the WAHL-related brightness temperature in the summer) are found at $12^{\circ} \mathrm{N}$, slightly north of the WAHL mean location in this longitude band. The percentage of grid points affected by temperature over the threshold is less than $30 \%$. During the spring, there is a slight northward progression of the brightness temperature maximum (Fig. 5). In the middle of June, the percentage of cloud-free pixels at $20^{\circ} \mathrm{N}$ increases to more than $70 \%$, while, simultaneously, the highest brightness temperature (in excess of $306 \mathrm{~K}$ ) shifts to $27^{\circ} \mathrm{N}$. From the middle of June to the beginning of September, the maximum of brightness temperature is observed to be located around this position with a maximum value in excess of $307 \mathrm{~K}$ and a percentage of cloud-free pixels exceeding $70 \%$ in July. Starting at the beginning of October, we see a progressive southward migration of the brightness temperature maximum. As

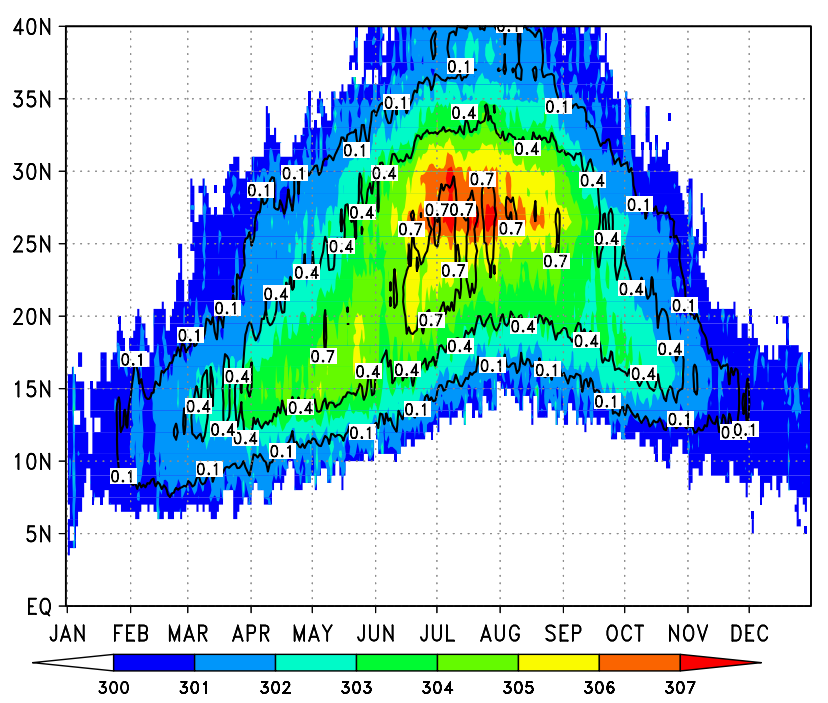

Fig. 5 Hovmoeller diagram (from $15^{\circ} \mathrm{W}$ to $10^{\circ} \mathrm{E}$ ) of the mean CLAUS-derived brightness temperature from 1984 to 2004 (K, color). Only pixels with values in excess of $300 \mathrm{~K}$ are used to compute the average. Black contours indicate the percentage of pixels used to compute the mean brightness temperature values 
discussed previously for the WAHL position, there exists a dissymetry in the low-level temperature cycle over West Africa, with a heating phase lasting nearly 6 months (February-July) and a cooling phase lasting only 3 months (September-November).

The seasonal evolution of the near-surface temperatures will have an impact on the seasonal cycle of the LLAT threshold (see Fig. 3) as they will influence the temperature in the 700-925 hPa throughout the year. However, other processes, such as temperature advection, may impact the temperature in the $925-700 \mathrm{hPa}$ levels. This is now investigated using the temperature tendency equation derived from the first law of thermodynamics, which can be written:

$\frac{\Delta T}{\Delta t}=\frac{Q}{C_{P}}-\left(\Gamma_{d}-\Gamma\right) w-\vec{V} \cdot \nabla T$

where $Q$ is rate of diabatic heating, $C_{p}$ is the specific heat capacity at constant pressure, $\Gamma_{d}$ is the dry-adiabatic lapse rate and $\Gamma$ is the vertical gradient of temperature, $w$ is the vertical velocity, $\vec{V}$ is the horizontal wind vector.

The first right-hand side term of Eq. (2) represents the diabatic heating related to sensible, latent and radiative heating. However, these products are not archived in the ERA-40 re-analysis (e.g. Knippertz and Fink 2008). Several approximations to the diabatic heating can be devised, for example using the radiation at the top of the atmosphere as in Knippertz and Fink (2008), but only during the winter season when latent heating is negligible. The second term on the right-hand side of Eq. (2) defines the adiabatic effects. The third term on the right-hand side of Eq. (2) corresponds to the horizontal advection. The last term plays an important role over West Africa as pointed out by Chou et al. (2001) and Peyrille and Lafore (2007).

In the following, we have analysed the spatial distribution of different terms likely to influence the evolution of temperature from 925 to $700 \mathrm{hPa}$ (and hence the LLAT) during two specific periods, winter (from January to March, Fig. 6) and summer (from July to September, Fig. 7). In particular, we focus on the surface temperature, the PBL depth and the temperature advection. The LLAT increases as a result of heating. The heating between 925 and $700 \mathrm{hPa}$ can result from two sources essentially: (1) surface warming as a result of solar radiation which is, to first order, what controls the increase of temperature in the PBL mixed layer, and the development of the PBL in the daytime, and (2) horizontal advection of temperature.

Whenever the PBL top reaches $700 \mathrm{hPa}$ or higher over an area characterized by large surface temperatures, then it is very likely that the LLAT is controlled by surface heating. On the other hand, if the LLAT is largest where the PBL top is below $700 \mathrm{hPa}$ and over an area characterized by surface temperatures below the maximum, then it is likely controlled by temperature advection.
The impact of surface sensible heating, which contributes to the first right-hand side term of Eq. (2), is analysed using the skin temperature from ECMWF. This spatiotemporal evolution of the skin temperature results from a variety of underlying surface characteristics (albedo, soil moisture, land cover, topography) and atmospheric processes (including seasonal cycle of insolation and cloud cover, for example). In the winter, over the continent, the largest mean daily skin temperatures are located over Ivory Coast and southern Burkina-Faso as well as over Senegal, Guinea-Bissau and Guinea (Fig. 6a). For instance, the largest skin temperatures are not found in the regions characterized by the deepest WAHL in the winter (see Fig. $4 a-c)$. By comparison, the maximum temperatures between 925 and $850 \mathrm{hPa}$ are found to the east of the domain (Fig 6a). A possible reason for this could be the presence of higher topography to the east of the domain together with a deeper PBL (Fig 6b). As shown in Fig. 1, the mean altitude of the ground is lower over the Western Sudanian region than to the east, where three large massifs (Dar Challa, Mount Cameroon and Darfur) lie over the Central African Republic, Southern Chad and Southern Sudan. Figure $6 \mathrm{c}$ displays the adiabatic term averaged from 925 to $700 \mathrm{hPa}$. To the north, subsidence associated with the northern branch of the Hadley cell leads to adiabatic warming over the Sahara and Sahel. The upward velocity between 925 and $700 \mathrm{hPa}$ in a stable atmosphere acts as a cooling process over the Sudanian region (see Fig. 2a). Hence, the southern side of the WAHL area (the mean position of the WAHL being indicated by the dotted rectangle in Fig. 6c) experiences adiabatic cooling. Finally, the horizontal advection term (averaged from 925 to $700 \mathrm{hPa}$ ) exhibits a cooling trend on average over the southern part of the WAHL. This is in agreement with the strong lower tropospheric wind field oriented toward the WAHL centre (Fig. 6d). Over the Sudanian region, a very weak impact is seen. In summary, the adiabatic and advection terms alone cannot explain the low-level warming that lead to the preferential position of the core of the WAHL over the Central African Republic. Rather, it is the presence of elevated terrain and deeper PBLs (and associated vertical mixing) which favours heating between 925 and $700 \mathrm{hPa}$. As a result the LLAT criterion favours the detection of the WAHL in this region.

The same analysis has been made during the summer season (Fig. 7). In the summer, the largest mean daily skin temperatures (in excess of $307 \mathrm{~K}$, Fig. 7a) and the deepest PBLs (in excess of 3,200 m, Fig. 7b) are nearly co-located over the Sahara. Both the adiabatic term and the horizontal advection term are negligible, except over the Sudanian region (Fig. 7c) and the Sahel (Fig. 7d), respectively. In this case also, it is the combination of high surface temperatures and deep PBLs that lead to the warming in the 
(a)

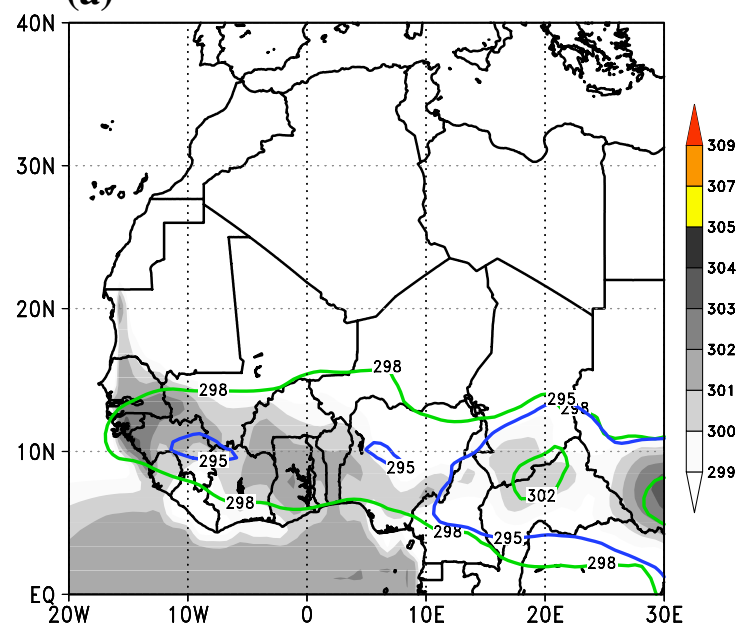

(c)

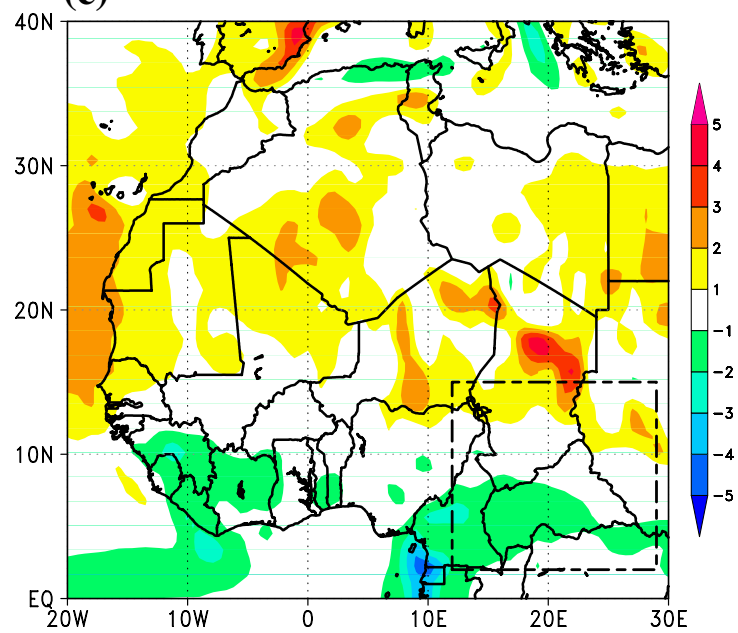

Fig. 6 Three months' climatological average (January-March) of: (a) skin temperature (K, color), as well as 925 and $850 \mathrm{hPa}$ temperature (green and blue contours, respectively, K); (b) boundary layer depth (m); (c) adiabatic term of the temperature tendency

925 to $700 \mathrm{hPa}$ layer. Consistently with this, the LLAT criterion favours the detection of the WAHL over the Sahara.

\subsection{Relationship with surface pressure}

In this section, we provide evidence that the LLAT criterion detects the low pressure associated with the heating in the low levels, and not that linked with mid-latitude depressions which are known to intrude over North Africa on a regular basis (Knippertz et al. 2003).

We have performed a spatial and temporal composite study of the location of the WAHL and the associated geopotential height at $1,000 \mathrm{hPa}$ for two periods, namely winter (January-March) and summer (July-September). In the following, we discuss the average position of the (b)

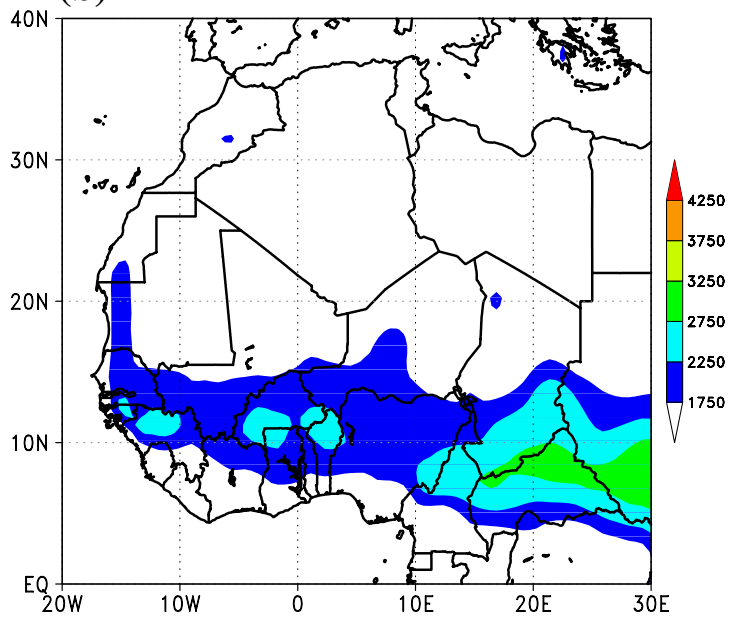

(d)

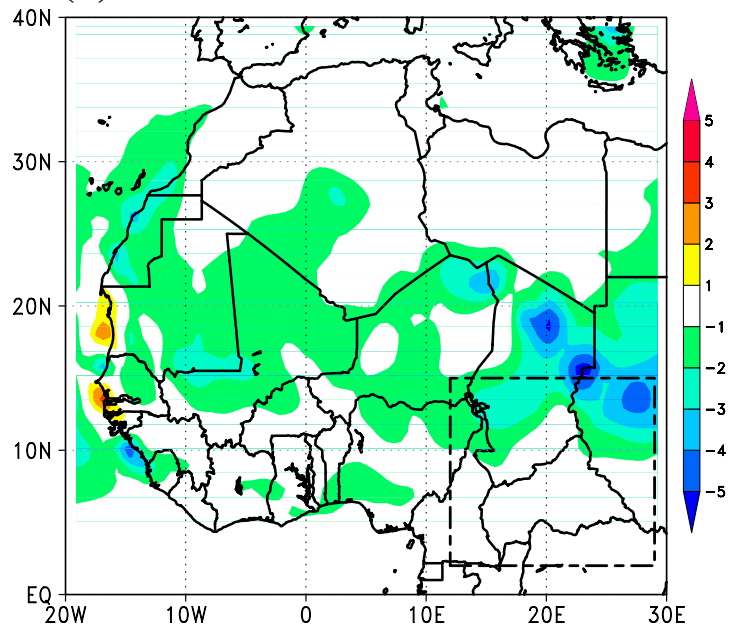

equation averaged from 925 to $700 \mathrm{hPa}$ (see text for more details, $\left.\mathrm{K} . d a y^{-1}\right)$; (d) horizontal advection term of the temperature tendency equation averaged from 925 to $700 \mathrm{hPa}\left(\mathrm{K} \mathrm{day}^{-1}\right)$

WAHL with respect to the surface pressure, using the notion of WAHL center. The center of the WAHL is defined as the average of the positions of the grid points at which the depth of the WAHL exceeds the threshold value, weighted by the WAHL depth. The position of the centre of the WAHL is computed on a daily basis for the months of the selected period (i.e. January-March and July-September) and is shown for the 1979-2001 period of the ERA-40 dataset. The average WAHL position during the winter season is $8.9^{\circ} \mathrm{N} ; 14.3^{\circ} \mathrm{E}$ (standard deviation \pm 2.44 and \pm 5.9 respectively) and $23.8^{\circ} \mathrm{N} ; 0^{\circ} \mathrm{W}$ (standard deviation $\pm 2.2^{\circ}$ and $\pm 4.1^{\circ}$ ) during the summer. Then, the $1,000 \mathrm{hPa}$ geopotential height and $925 \mathrm{hPa}$ wind fields are centred with respect to the WAHL center (indicated by the origin point in Fig. 8). As previously discussed, the WAHL is generally detected as a single wide area. However, when 
(a)

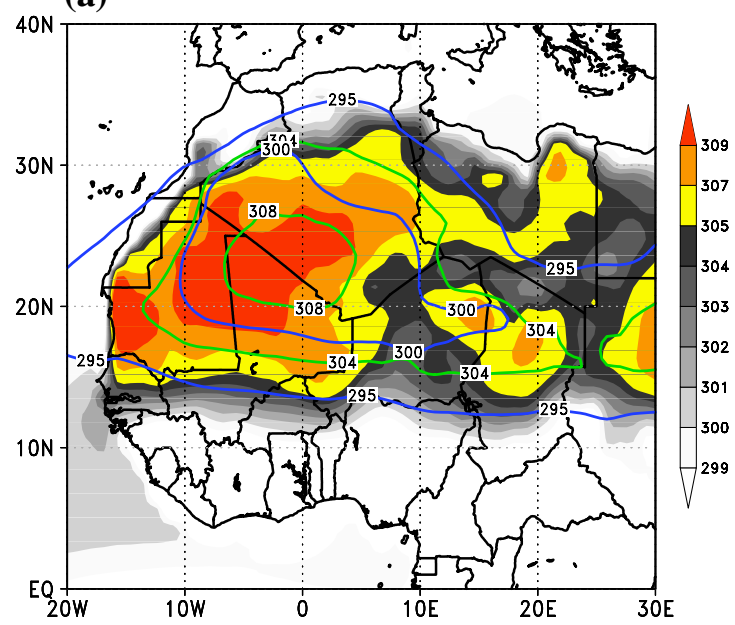

(c)

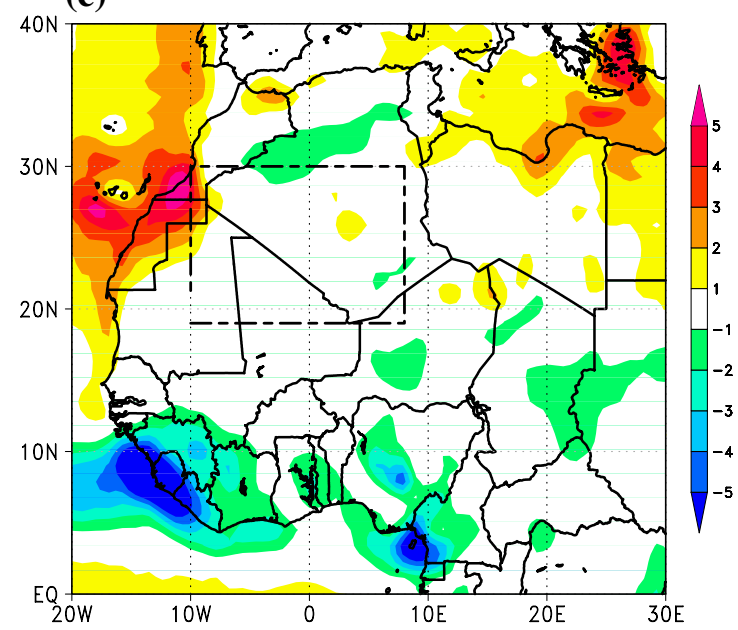

(b)

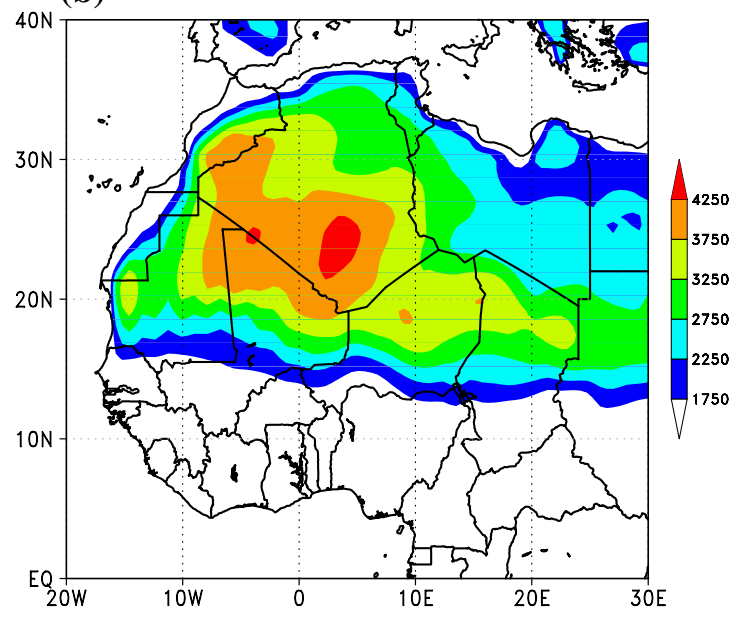

(d)

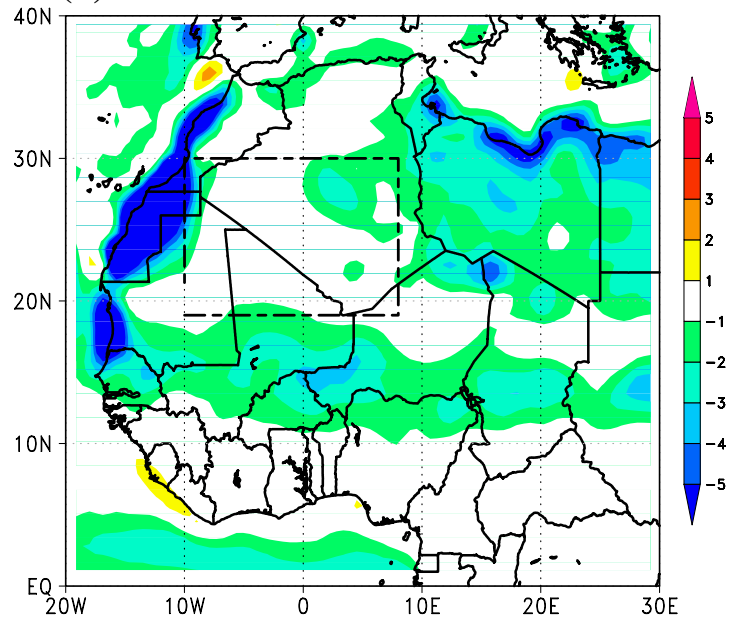

Fig. 7 Same figure as Fig. 6, but for the July-September period. (a) Temperature; (b) Boundary layer height; (c) Adiabatic term; (d) Horizontal advections term

it is not the case, i.e. there exist several WAHL centers remote from one another, we always find the widest WAHL also to be the deepest. Moreover, the shallower and narrower secondary WAHL cores are generally found to be relatively close to the main WAHL (i.e. the deepest and largest WAHL core). This implies that the WAHL centre is almost always detected within the main WAHL, in the case that more than one WAHL core is detected.

During the winter, the position of the WAHL exhibits a large spatial variability and large longitudinal extension. The WAHL takes the form of an elongated heat trough. The wind field is consistent with this, which shows strong convergence along the southern fringes of the WAHL (Fig. 8a). The area of minimum $1,000 \mathrm{hPa}$ geopotential height appears closely linked with the ITD, particularly to the west of the WAHL center. This is consistent with Fig. 4a-c. The minimum of 1,000 hPa geopotential height is located within $\pm 5^{\circ}$ of latitude of the heat trough.
Because the location of the WAHL centre is calculated by taking into account an ensemble of grid points composing the WAHL, it cannot match exactly the position of the minimum of geopotential which is a more local variable associated with only a few grid points, at most.

During the summer season, the composited WAHL takes the form of a circular low (Fig. 8), consistently with Fig. $4 \mathrm{~g}-\mathrm{i}$. The minimum of 1,000 $\mathrm{hPa}$ geopotential height is nearly co-located with the position of the WAHL. The depression is quite marked, with a $1,000 \mathrm{hPa}$ geopotential height under $74 \mathrm{~m}$. As a consequence, the $925 \mathrm{hPa}$ winds are seen to spiral around the trough. The centre of the WAHL (i.e. the origin of the graph) is located to the east of the WAHL (contours). This is essentially linked to the way the WAHL center is computed (i.e. accounting for a wide area). In the summer, while the WAHL is located to the west of the Hoggar, it exhibits a large day-to-day variability (particularly north and south of the Hoggar) which 
Fig. 8 Composite study of mean $925 \mathrm{hPa}$ wind field (vectors, $\mathrm{m} \mathrm{s}^{-1}$ ), 1,000 $\mathrm{hPa}$ geopotential height $(\mathrm{m}$, color) and WAHL occurrence frequency (black contours) centred with respect to the WAHL center located in the origin of the graph $(0,0)$ in winter (a) and summer (b) (a)

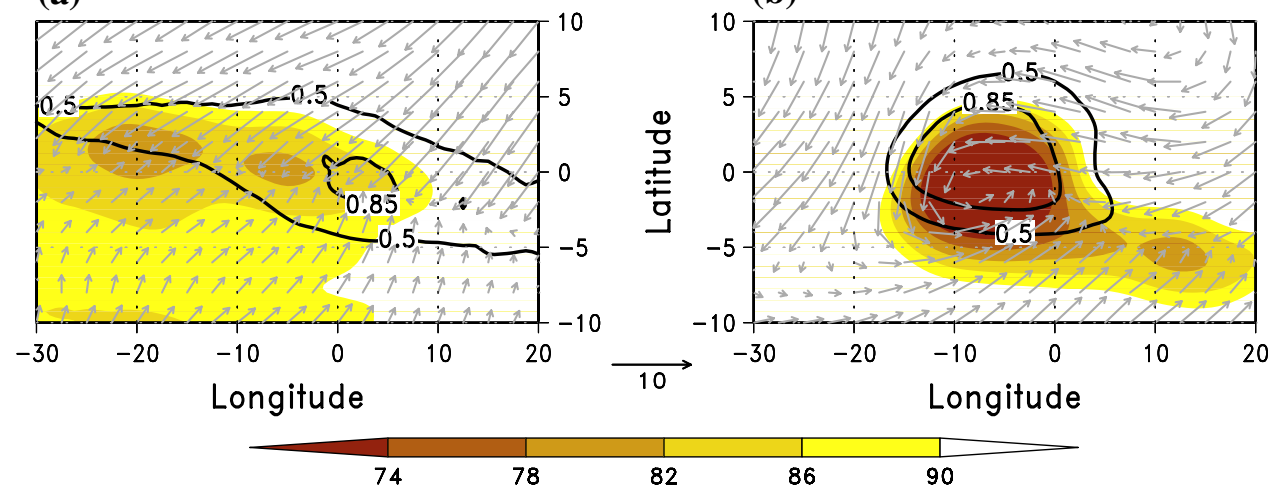

is not captured while plotting the mean WAHL occurrence frequency, but strongly influences the location of the WAHL centre, positioning it on the eastern edge of the WAHL.

\subsection{Diurnal cycle of the Heat Low}

We now compare the climatological WAHL occurrence frequency averaged between June and October at 0600 UTC with those obtained at 0000, 1200 and 1800 UTC. The summer season was selected due to the fact that the WAHL is quasi-stationary during that period, and because its impact on the circulation at low levels is strongest. Figure 9a shows the mean location of the WAHL at 0600 UTC from June to October, the maximum of occurrence frequency (in excess of 80\%) being located to the southwest of the Hoggar mountains. Figure 9b, c and d illustrate the anomaly in WAHL occurrence frequency at 0000, 1200 and 1800 UTC, with respect to that at 0600 UTC. The thresholds used to detect the WAHL were computed separately for each time frame. The average threshold vales are 2,424, 2,416, 2,423 and 2,431 $\mathrm{m}$ at 0000, 0600, 1200 and $1800 \mathrm{UTC}$, respectively.

Negative values indicate a higher occurrence frequency at 0600 UTC than at other times. The smallest anomalies were found at 0000 UTC (Fig. 9b). Regions where the WAHL occurrence is largest at 0600 UTC, exhibit a small occurrence frequency anomalies (the difference is less than $15 \%)$. Rather anomalies appear on the outskirts of the core of the WAHL. During the daytime, there is a large positive anomaly of WAHL occurrence over the orography, especially over the Hoggar mountains, where the WAHL occurrence is seen to increase by more than $25 \%$ at midday (Fig. 9c) and by more than $20 \%$ at 1800 UTC (Fig. 9d). Because we are considering anomalies in WAHL occurrence frequency here, the decrease of the WAHL detection at 1200 UTC and 1800 UTC with respect to 0600 UTC (Fig. 9c and d) may be explained by the increase of the LLAT over the elevated terrain (Atlas, Hoggar and Tibesti mountains) and, hence, a relative decrease of the LLAT over the rest of the continent. At 1800 UTC, the inflow of cooler maritime air from the Atlantic near the Saharan west coast could also partly explain this decrease, as this will affect the LLAT. This is likely to be related to the fact that the air above elevated terrain warms more quickly in the course of the day than it does over the surrounding plains, as mountains tend to act as heat lows. As a result, the diurnal cycle of the WAHL appears to exhibit oscillations of larger longitudinal than latitudinal amplitude during the summer season.

\section{The onset of the Saharan heat low and its link with the West African Monsoon}

Using gridded rain gauge data for the 1968-1990 period, Sultan and Janicot (2003) have shown that the climatological date of the monsoon onset was 24 June \pm 8 days. Figure 4 shows that around that period (between June and July), the WAHL indeed experienced a north-westward displacement from $19^{\circ}-23^{\circ} \mathrm{N}$ to $22^{\circ}-27^{\circ} \mathrm{N}$ (for WAHL occurrence frequencies in excess of $80 \%$ ), consistently with Ramel et al. (2006). In other words, during this period, the WAHL makes a transition to its summer position over the Sahara, over which it remains in place until September (during this period the WAHL is generally referred to as the Saharan heat low -SHL- in the literature). Also Fig. 3 shows that the largest WAHL depths are found shortly after mid-June.

In the following, we investigate the possible relationship between the monsoon onset and the onset of the SHL, i.e. the climatological date at which the WAHL reaches its summer location over the Sahara. To do so, we have performed an empirical orthogonal function (EOF) analysis of the WAHL occurrence frequency between May and November. In Fig. 10a, the first EOF component, which explains more than $32 \%$ of the total variance, corresponds to the area covered by the WAHL as detected from May to November 
(a)

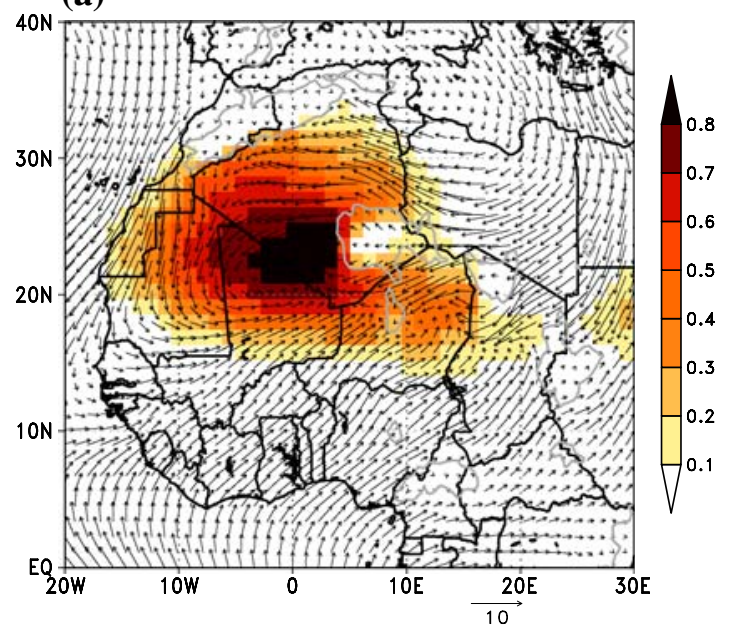

(c)

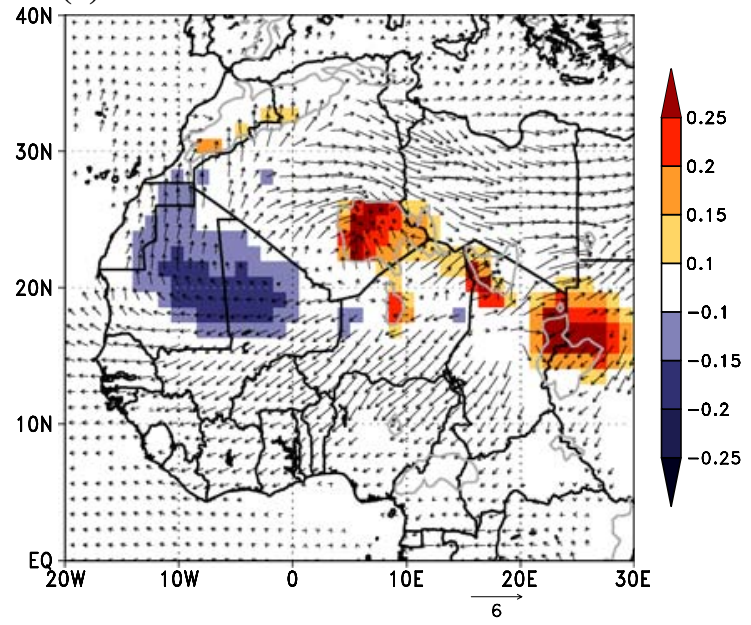

Fig. 9 a Mean WAHL occurrence frequency for the June-October period at $0600 \mathrm{UTC}$ (shaded). The mean $925 \mathrm{hPa}$ wind field (vectors, in $\mathrm{m} \mathrm{s}^{-1}$ ) is overlain. Anomaly of the WAHL occurrence frequency

(Fig. 10a). The second EOF component (12\% of the total variance) displays a bi-polar pattern (Fig. 10b, c). The positive values of the second component (Fig. 10b, d) correspond to an increase of the WAHL detection over a large part of the Sahara during the summer (between mid-June and mid-September). The WAHL recomposition using these two EOFs displays both the propagation of the WAHL between Spring and Fall, and the stationary location over the Sahara during the summer as shown in Fig. 4. Thus, we define the SHL period as being the period when both these components are positive. The onset of the SHL is defined as the first day for which the second component becomes positive (Fig. 10b). This method is applied for each of the 23 years of the ERA-40 period. The mean date of the SHL onset is found to be 20 June \pm 9 days, i.e. just before the climatological monsoon onset defined by Sultan and Janicot (2003). The end of the SHL period in the climatological sense occurs on 17 September \pm 7 days, i.e. 89 days after the onset. (b)

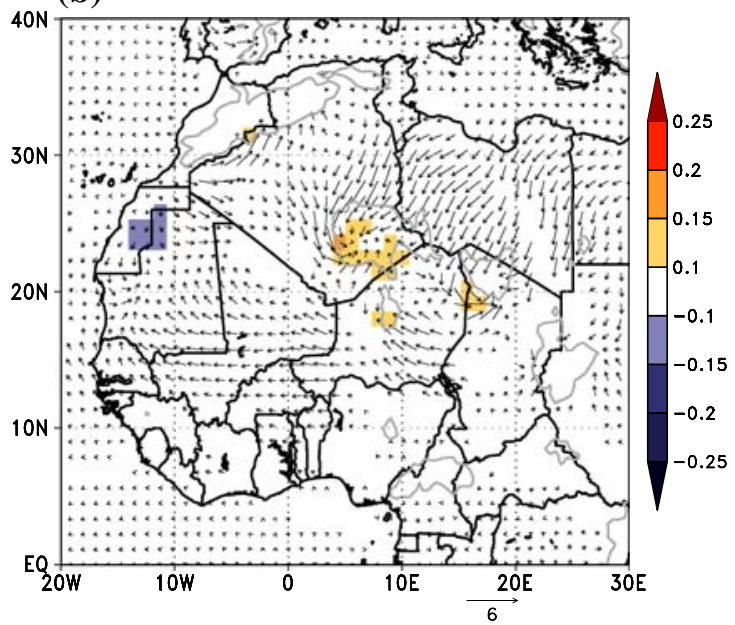

(d)

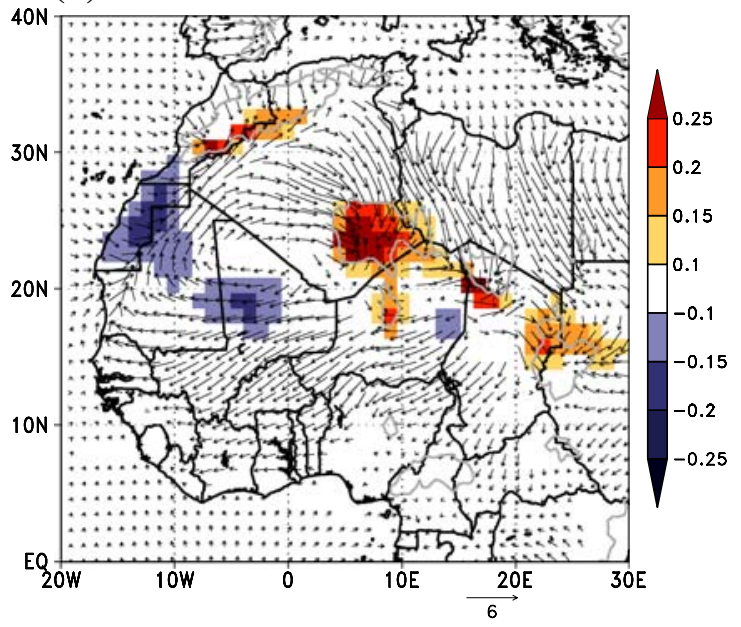

and $925 \mathrm{hPa}$ wind field between 0000 and 0600 UTC (b), 1200 and 0600 UTC (c) and 1800 and $0600 \operatorname{UTC}(\mathbf{d})$

To document the relationship between the seasonal evolution of the WAHL and the African monsoon, the time series of variables of interest are plotted with respect to $t_{0}$, which defines the time of the SHL onset. For consistency, only the period 1984-2001 (common to both ERA-40 an CLAUS) is used.

As shown in Fig. 11a, the largest WAHL depths are obtained a few days after the onset (around $t_{0}+15$ ). However, the difference between the WAHL depth and the LLAT threshold value increases drastically just after the onset. This suggests that the WAHL attains its peak intensity shortly after the onset, roughly between $t_{0}+5$ and $t_{0}+65$. It reaches a plateau between $t_{0}+5$ and $t_{0}+30$ and a maximum at $t_{0}+31$. Values lower than in the pre-onset conditions are found after $t_{0}+75$. This indicates a particularly deep WAHL over the Sahara during 2 months (between $t_{0}+5$ and $t_{0}+65$ ) which is not observed elsewhere over the West Africa. This is consistent 
(a)

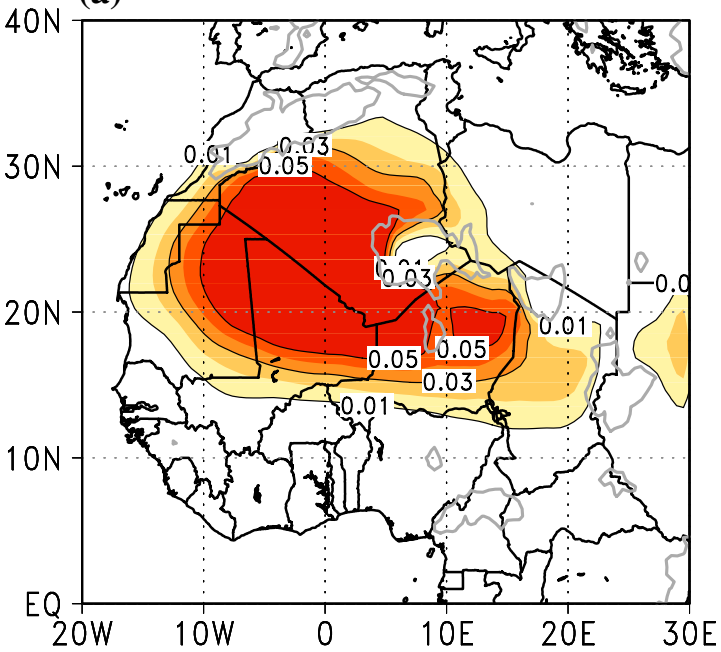

(b)

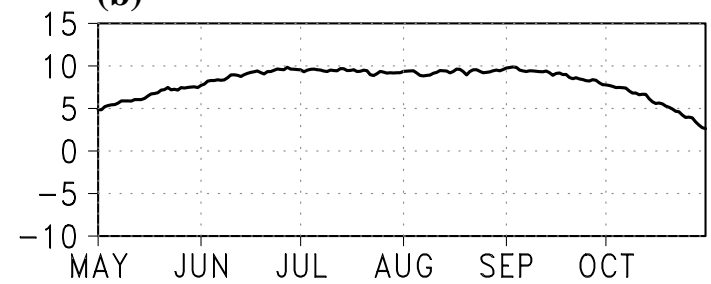

Fig. 10 a Spatial pattern of the first component of the EOF analysis of the WAHL location from May to October. The grey lines to terrain elevation ( $800 \mathrm{~m}$ above sea level) and delineate the major orographic

with the suggestion made by Sijikumar et al. (2006) that the onset of the monsoon is observed nearly coincidentally with a deepened WAHL.

Following a remark of Parker et al. (2005a), Sultan et al. (2007) have shown that the monsoon onset is associated with the increase of the $925 \mathrm{hPa}$ wind speed at 0600 UTC. This is consistent with the increase of the WAHL thickness and the meridional gradient of geopotential. The strongest south-westerly monsoon winds are observed shortly after the onset (Fig. 11b). At $t_{0}$, the WAHL reaches the area free of topography to the west of the Hoggar (see Fig. $4 \mathrm{~g}$ ) and, examining the vorticity field, it appears that a wide region of intense cyclonic circulation occurs, spanning from $15^{\circ}$ to $30^{\circ} \mathrm{N}$. The region of enhanced vorticity appears to result from the merging of two distinct areas of vorticity seen before the onset: (1) one associated with the cyclonic circulation at the ITD which progresses northward in the course of the season, and (2) one located over the Sahara, around $27^{\circ} \mathrm{N}$, which is associated with the flowsplitting on the northern edge of the Hoggar. The existence of this large positive vorticity feature over the Sahara during the summer is arguably an important feature of the West African Monsoon as it is concomitant with the presence of the deepest WAHL. Moreover, during the heart (c)

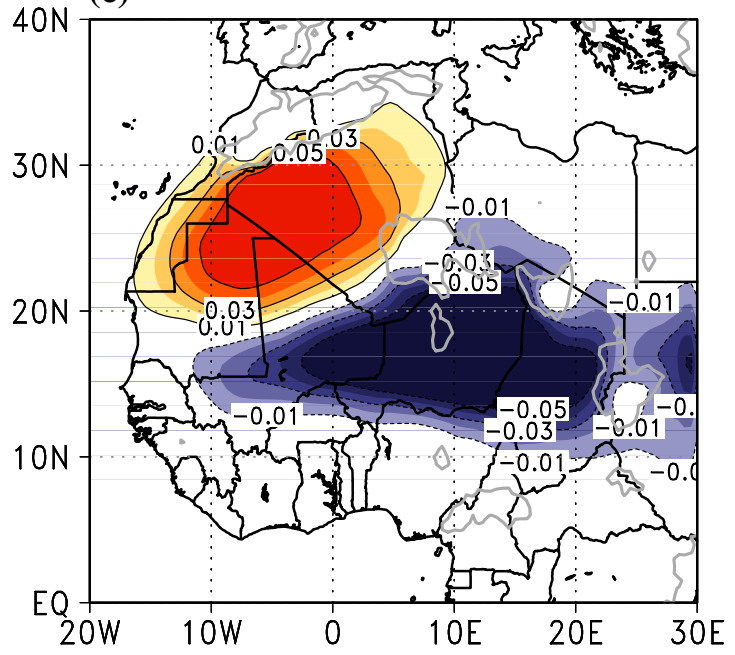

(d)

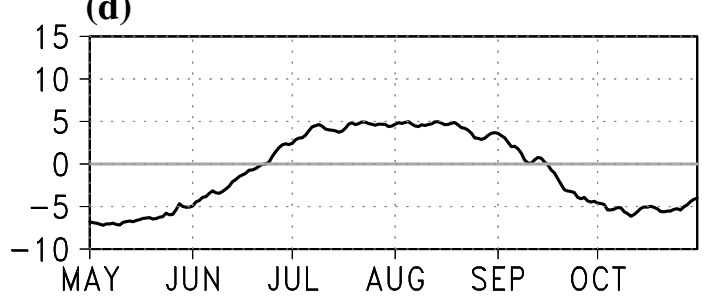

features. b Temporal evolution of the first component of the EOF. c and d displays the same results as (a) and (b), respectively, but for the second component of the EOF

of the rainy season over the Sahel (i.e. from mid-July to early September), the vorticity field also appears to highlight what could be the large-scale signature of the convection around $10^{\circ} \mathrm{N}$.

Finally, at $t_{0}$, the northern edge of the region characterized by brightness temperatures in excess of $300 \mathrm{~K}$ (Fig. 11b) progresses northward very quickly from 22 to $30^{\circ} \mathrm{N}$, and it remains this far north until $t_{0}+70$. This corroborates and generalizes the results of Ramel et al. (2006), based on a single model simulation for the year 1992. These authors observed a similar temporal discontinuity of the simulated surface temperature field evolution, between $16^{\circ} \mathrm{N}$ and $22^{\circ} \mathrm{N}$, around the end of June 1992, and they connected this evolution with the monsoon onset. Moreover, the low brightness temperatures (under $270 \mathrm{~K}$, Fig. 11b) show a decrease of convective activity between $t_{0}$ and $t_{0}+15$ : after $t_{0}+15$, convective activity is shifted to around $10^{\circ} \mathrm{N}$. This evolution is clearly identified by Sultan and Janicot (2003) as the start of the rainy season over the Sahel.

Sultan and Janicot (2003) have shown that the time of the monsoon onset was approximately mid-way through this period of suppressed convection. Hence, based on Fig. 11, the present study suggests that the setting-up of the 
Fig. 11 (a) Temporal evolution of the WAHL thickness (m, black solid line) centred on the date of the SHL onset $\left(t_{0}\right.$, see text for more details) and difference between the WAHL thickness and the WAHL detection threshold (red line, $\mathrm{m}$, scale on the right-hand side). (b) Hovmoeller diagram of the vertical component of vorticity at $925 \mathrm{hPa}$ (light grey corresponds to values between 0 and $10^{-6} \mathrm{~s}^{-1}$, dark grey corresponds to values in excess of $10^{-6} \mathrm{~s}^{-1}$ ). 300 and $270 \mathrm{~K}$ contours of CLAUS-derived brightness temperature are indicated by the red and blue solid lines, respectively. The $925 \mathrm{hPa}$ wind speed is indicated in yellow $\left(\mathrm{m} \mathrm{s}^{-1}\right)$. The thick black solid line indicates the mean position of the WAHL. The variables are averaged from $15^{\circ} \mathrm{W}$ to $10^{\circ} \mathrm{E}$

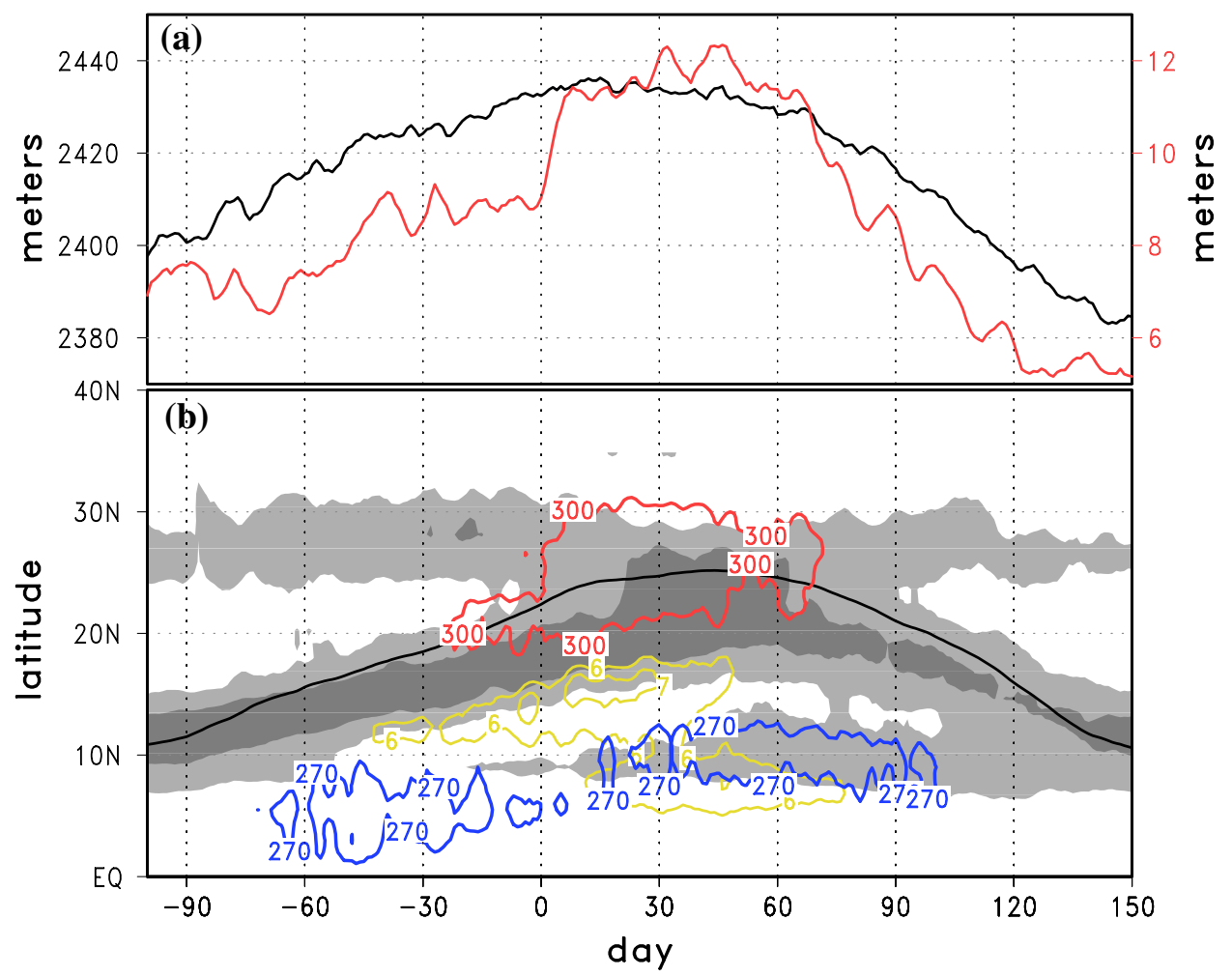

SHL ( $t_{0}$ in Fig. 11a) occurs approximately 7 days before the monsoon onset $\left(t_{0}+7\right.$, i.e. in the middle of suppressed convection period in Fig. 11b). For the 1984-2001 period, the lag between the monsoon and the SHL onsets is also calculated by comparing the climatological SHL onset date with the climatological monsoon onset date obtained using the annual rain gauge data as in Sultan and Janicot (2003) and available from http://www.locean-ipsl.upmc.fr/ bslod/. We find 20 June \pm 11 days and 25 June \pm 9 days for the SHL onset and monsoon onset, respectively, which yields a difference of 5 days. Given the variability associated with both values, this difference is quite consistent with the value of 7 days found earlier.

Several studies (e.g. Eltahir and Gong 1996; Zheng and Eltahir 1998) have highlighted the role of complex surface-atmosphere interactions to explain the maintenance of the convective activity and the strong monsoon flux south of the convective band (i.e. around $5^{\circ} \mathrm{N}$ ) nearly 90 days after the SHL onset whereas the WAHL weakens and the meridional gradient of the geopotential diminishes.

\section{WAHL detection in 2006}

The seasonal evolution of the WAHL in 2006 (the year of the AMMA SOP) is now analysed and compared with the climatological results.
The year 2006 is not part of the ERA-40 re-analysis effort, hence we used the ECMWF operational analyses. Furthermore, the ECMWF model has been improved with a new dust climatology (Tompkins et al. 2005), and this change generates some differences with respect to the ERA-40 re-analysis. For instance, in 2005 and 2006, the LLAT was found to be systematically larger throughout the year, possibly due to radiative effects of dust and other evolutions of the ECWMF model. Nevertheless, the determination of daily thresholds ensures some consistency in the determination of the daily WAHL frequency occurrence using ERA-40 re-analysis and operational analyses. A large part of the monthly mean location and wind circulation appear quite similar to the climatology.

Figure 12 illustrates the main differences of the WAHL location which occur in 2006 with respect to the climatology. In January and February, the WAHL is seen southwest of the Darfur mountains, with a positive anomaly of occurrence frequency with respect to the climatology larger than 30\% (2006 deeper). This effect could be associated with the change of dust climatology in the model, and it is interesting to note that the location where the WAHL occurrence increases is downstream of the Bodélé depression $\left(18^{\circ} \mathrm{N} ; 20^{\circ} \mathrm{E}\right)$ which is known to be an active dust sourcedust source in the winter. The wind field anomaly indicates a large eastward anomaly of the Harmattan flow. South of $20^{\circ} \mathrm{N}$, the anomaly in wind direction seems to be associated with the anomaly of WAHL position, with 
(a) JAN - FEB

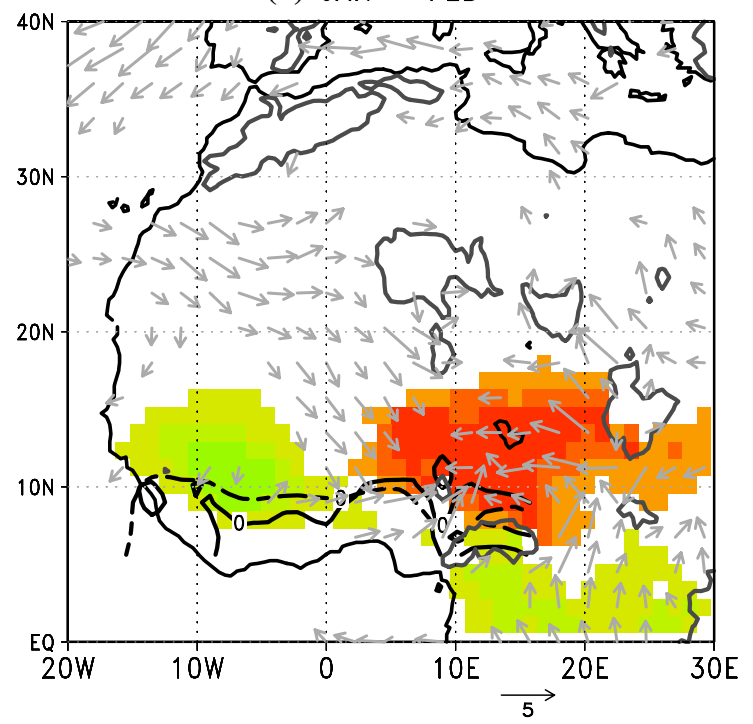

(c) JUN

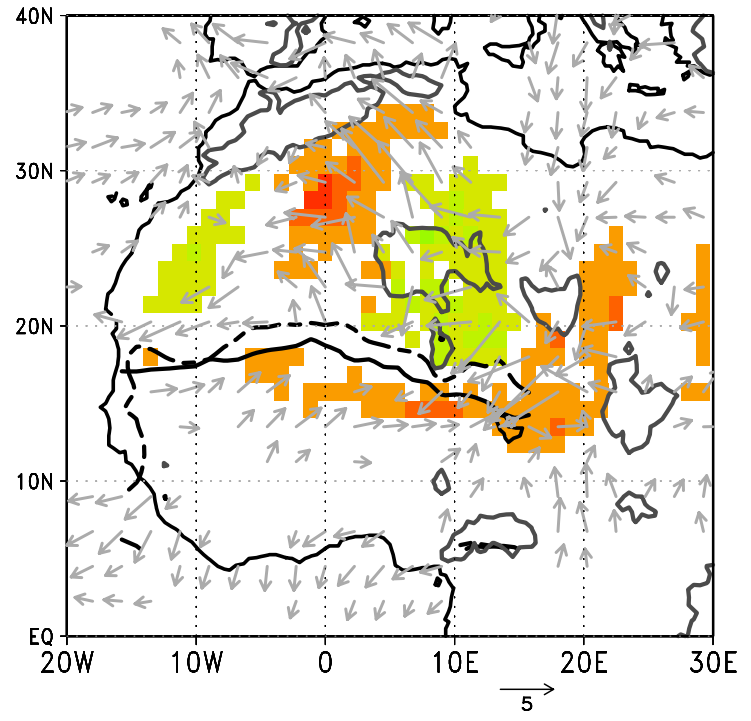

Fig. 12 Monthly mean anomaly of the WAHL occurrence frequency (color) and wind at $925 \mathrm{hPa}$ (vectors) in 2006 with respect to the climatology when differences are observed, in January and February (a),

divergence/convergence in the region of the negative/ positive WAHL anomaly. The position of the ITD in January and February 2006 is close to its climatological position.

In April, a large anomaly of LLAT is seen to the northwest of the climatological position of the WAHL. This LLAT anomaly is not connected to a displacement of the WAHL, but rather is due to an episode of extra-tropical forcing which was the dominant signal over the whole of West Africa for nearly 20 days. Strong anticyclonic circulation appears on the southern side of south-west winds, which are associated with cyclonic circulation over the (b) APR

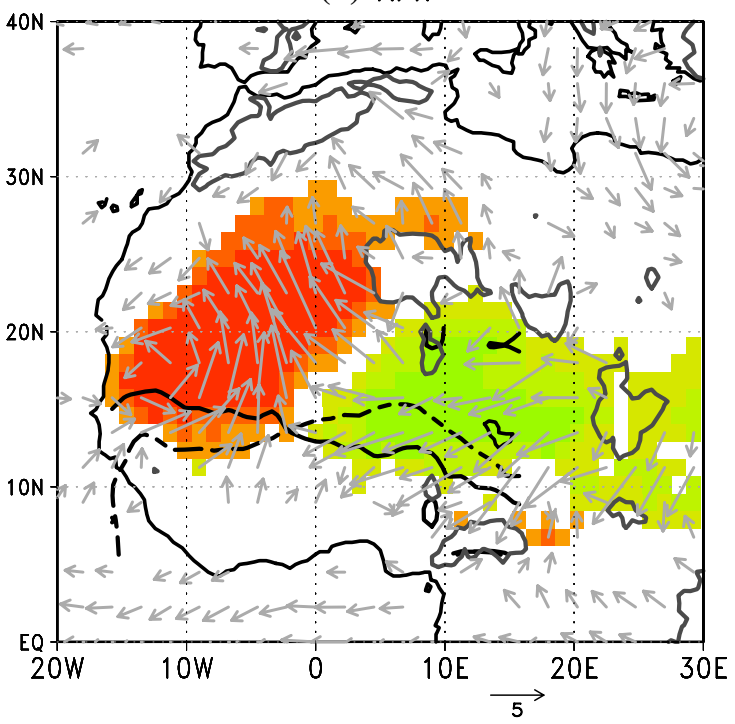

(d) $A \cup G$

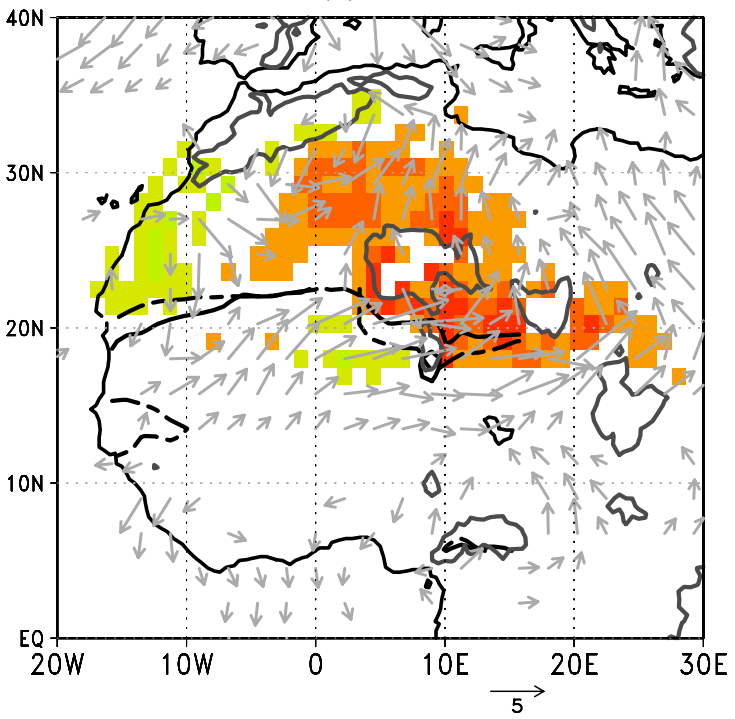

April (b), June (c) and August (d). The solid line indicates the ITD location in 2006. The dashed line indicates the climatological ITD

Atlantic. This strong anticyclonic circulation acts to reduce the advection of cool air from the Atlantic, and warm air is effectively "recycled" by the south-westerlies: therefore the anticyclone favours the increase of the temperature in the low troposphere, that in turn generated the dynamical dilatation of the atmospheric layer between 925 and $700 \mathrm{hPa}$, which was detected by our method. Ultimately, this led to the formation of a tropical plume (as identified by Knippertz et al. 2003) around 23 April, associated with a negative anomaly of geopotential at $300 \mathrm{hPa}$ over Morocco, a large cloud band oriented south-west to north-east over West Africa and a large daily rainfall anomaly over 
the northern part of Ghana and over Burkina Faso (not shown). The influence of the tropical plume could be observed during the second half of April, in the form of a large positive anomaly of GPS-derived precipitable water vapour observed in Gao, Mali and Niamey, Niger (about $+20 \mathrm{~kg} \mathrm{~m}^{-2}$ and $+30 \mathrm{~kg} \mathrm{~m}^{-2}$, respectively, O. Bock personal communication). The negative anomaly of the LLAT south of Tibesti is associated with an increase of the north-easterlies and divergent wind. Despite the delay of the monsoon onset in 2006 (Janicot and Sultan 2007), the SHL onset occurred on 18 June, close to the climatological value. As discussed in Drobinski et al. (2007), the anticyclone climatologically centred above Libya was located above Tunisia in 2006, which led to an enhanced southwestward flow east of the Hoggar with respect to the climatology. This anomaly could explain the general southward anomaly of the ITD in June 2006. In August 2006, the WAHL anomaly is large over the Hoggar, and is associated with a strong convergent wind field anomaly, an increase of the monsoon flow and a northward anomaly in the position of the ITD.

\section{Summary and conclusions}

In this study, we propose a method to detect the WAHL in order to monitor its climatological seasonal displacement over West Africa during the period 1979-2001. The LLAT, a variable defined as the difference of geopotential heights at 700 and $925 \mathrm{hPa}$ at $0600 \mathrm{UTC}$, is used to detect the dilatation in the low levels generated by an increase of the temperature. The WAHL is defined as the region for which the LLAT exceeds a certain threshold: the threshold is determined as $90 \%$ of the cumulative probability distribution function of LLAT computed over the West African domain. We also show that our method reliably positions the WAHL over areas of high surface temperatures and low surface pressures, and that it is effective at detecting heat lows. The inter-annual variability of the LLAT implies that the WAHL be detected using a daily threshold independent from one year to another. Thus, this method could be used in the operational framework by forecasters to locate the WAHL on a daily time scale. Furthermore, this robust method can be used to diagnose the WAHL in climate, global or mesoscale models.

In the course of the year, the climatological WAHL is shown to migrate north-westward from a position south of the Darfur mountains in the winter (November to March) to a location over the Sahara, between the Hoggar and the Atlas mountains, during the summer (June to September). The displacement of the WAHL between these two positions is consistent for each of the years of the ERA-40 analyses. The temperature tendency equation was used to investigate the processes controlling the displacement of the WAHL, and more particularly the heating in the low levels. The northward propagation of the WAHL is to first order associated with the northward displacement of the maximum of solar radiation at the surface, which increases the surface temperature and controls the depth of the PBL. The other terms of the temperature tendency equation (advection and adiabatic processes) are shown to be less important. Although the use of the temperature tendency equation has proved to be insightful, there is still a need for detailed investigation of the link between the dynamics of the WAHL and the West African monsoon at the regional scale.

The specific period of the onset of the WAHL in its summer location over the Sahara is analysed using empirical orthogonal functions. The climatological onset of the SHL occurs around 20 June, i.e. just before the climatological monsoon onset date provided by Sultan and Janicot (2003). The present study suggests that the SHL onset occurs approximately 5 days before the monsoon onset for the 1984-2001 period. This is confirmed independently by comparing the SHL onset date and the monsoon onset date for the 1984-2001 period. Our study also confirms (at the climatological scale) the results of Ramel et al. 2006 and Sijikumar et al. (2006) who suggested that the onset of the monsoon is observed nearly coincidentally with an increase of the surface temperature over the Sahara and a deepening of the WAHL. In the future, the use of mesoscale models will enable to analyse the specific role of the WAHL in the WAM circulation during the onset period.

The seasonal evolution of the WAHL for the year 2006 (the year of the AMMA SOP) is analysed and compared with the climatological results. The operational ECMWF analyses with an improved dust scheme was used for that purpose, which may be responsible for the overall thickening of the LLAT in 2006 with respect to the climatology. Except in April, the spatial distribution of the WAHL remains relatively unchanged with respect to the climatology. The onset of the SHL in 2006 occurs on 18 June, which is close to the climatological date, in spite of the delay in the onset of the rainy season in Sahel.

This study is the first to look in depth at the seasonal cycle of the WAHL and its links with the WAM. It also provides a framework (i.e. a robust, objective method to detect the WAHL) for future studies on the role of the WAHL in African climate, or its impact on adjacent regions such as the Mediterranean basin using climate models, as well as processes studies in the Sahara using mesoscale models.

Acknowledgments Based on a French initiative, AMMA was built by an international scientific group and is currently funded by a large number of agencies, especially from France, UK, US and Africa. It has been the beneficiary of a major financial contribution from the European Community's Sixth Framework Research Programme. 
Detailed information on scientific coordination and funding is available on the AMMA International web site http://www.ammainternational.or. The authors wish to thank the two anonymous referees for their constructive and much appreciated comments.

Open Access This article is distributed under the terms of the Creative Commons Attribution Noncommercial License which permits any noncommercial use, distribution, and reproduction in any medium, provided the original author(s) and source are credited.

\section{References}

Brest CL, Rossow WB, Roitier MD (1997) Update the radiance calibration for ISCCP. J Atmos Ocean Tech. doi: 10.1175/ $1520-0426$

Buckle C (1996) Weather and climate in Africa. Harlow, UK

Chou C, Neelin JD, Su H (2001) Ocean-atmosphere-land feedbacks in idealized monsoons. Quart J R Met Soc 127:1869-1891

Diedhiou A, Janicot S, Viltard A, de FTlice P (1998) Evidence of two regimes of easterly waves over West Africa and the tropical Atlantic. Geophys Res Let 25:2805-2808

Drobinski P, Bastin S, Janicot S, Dabas A, Delville P, Reitebuch O (2007) Role of scale interactions and orograpgy on the late northward propagation of the West African monsoon in summer 2006 in the region of Niger/Mali. in revision in J Geophys Res

Drobinski P, Sultan B, Janicot S (2005) Role of the Hoggar massif in the West Africa monsoon onset. Geophys Res Lett 32. doi: 10.1029/2004GL020710

Eltahir EAB, Gong C (1996) Dynamics of wet and dry years in West Africa. J Clim 9:1030-1042

Fink AH, Reiner A (2003) Spatio-temporal variability of the relation between African esterly waves and west African squall lines in 1998 and 1999. J Geophys Res 108

GallTe H, Moufouma-Okia W, Brasseur O, Dupays I, Marbaix P, Messager C, Ramel R, Lebel T (2004) A high resolution simulation of the West African rainy season using a regional climate model. J Geophys Res 109. doi: 10.1029/2003JD004020

Janicot S, Sultan B (2007) The large scale context on the West African monsoon in 2006. Clivar exchanges, April 2007

Kallberg P, Berrisford P, Hoskins B, Simmons A, Uppala S, Lamy-Thepaut S, Hine R (2005) ERA-40 atlas. Technical report, ERA-40 Project Report Series, ECMWF, Shinfield Park, Reading, UK, $191 \mathrm{pp}$

Knippertz P, Fink AH (2008) Dry-season precipitation in tropical West Africa and its relation to forcing from the extratropics. Mon Weath Rev. doi:10.1175/2008MWR2295.1

Knippertz P, Fink AH, Reiner A, Speth P (2003) Three late summer/ early autumn cases of tropical-extratropical interactions causing precipitation in Northwest Africa. Mon Weather Rev 131:116135

Lafore J-P, Chapelet P, Mumba Z, Chapelon N, Dufresne M-C, Agbabu R, Abdoul-Aziz A, Hamidou H, Asencio N, Couvreux F, Nuret M, Garba A (2007) Forecaster's guide for west african synthetic analysis/forecast. Technical report, Deliverable for AMMA available from https://www.ammaeu.org/ 2007

Lavaysse C, Diedhiou A, Laurent H, Lebel T (2006) African Easterly Waves and convective activity in wet and dry sequences of the West African Monsoon. Clim Dyn. 27(2/3):319-332

Parker D, Burton RR, Diongue-Niang A, Ellis R, Felton M, Taylor CM, Thorncroft C, Bessemoulin P, Tompkins AM (2005a) The diurnal cycle of the West African monsoon circulation. Quart J R Met Soc 131:2839-2860

Parker DJ, Thorncroft CD, Burton R, Diongue-Niang A (2005b) Analysis of the African easterly jet, using aircraft observations from the JET 2000 experiment. QJR Meteorol Soc 131:1461-1482

Peyrille P, Lafore JP (2007) An idealized two-dimentional framework to study the West African monsoon, part ii: large scale advection and the diurnal cycle. J Atmos Sci 64:2783-2803

Racz Z, Smith RK (1999) The dynamics of the heat low. QJR Meteorol Soc 125:225-252

Ramel R, GallTe H, Messager C (2006) On the northward shift of the west african monsoon. Clim Dyn 26(4):429-440

Redelsperger JL, Thorncroft CD, Diedhiou A, Lebel T, Parker DJ, Polcher J (2006) African Monsoon Multidisciplinary analysis: an international research project and field campaign. Bull Am Meteorol Soc 87:1739-1746

Semazzi FHM, Sun L (1997) The role of orography in determining the Sahelian climate. Int J of Climatol 17:581-596

Sijikumar S, Roucou P, Fontaine B (2006) Monsoon onset over Sudan-Sahel: similuation by the regional scale model MM5. Geophys Res Lett 33. doi:10.1029/2005GL024819

Sultan B, Janicot S (2003) The West African Monsoon dynamics. part II: the "preonset" and "onset" of the summer monsoon. J Clim 16(21):3407-3427

Sultan B, Janicot S, Drobinsky P (2007) Characterisation of the diurnal cycle of the West African Monsoon around the monsoon jump. J Clim 20:4014-4032

Thorncroft CD, Blackburn M (1999) Maintenance of the African easterly jet. QJR Meteorol Soc, 125(555):763-786

Thorncroft CD, Hodges K (2001) African easterly wave variability and its relationship to Atlantic Tropical cyclone activity. J Clim 14:1166-1179

Tompkins AM, Cardinali C, Morcrette JJ, Rodwell M (2005) Influence of aerosol climatology on forecasts of the African Easterly Jet. Geophys Res Lett 32. doi: 10.1029/2004GL022189

Uppala S, Kallberg PW, Simmons AJ, Andrea U, and 42 others (2005) The ERA-40 reanalysis. QJR Meteorol Soc 131:2961-3012

Zheng X, Eltahir EAB (1998) The role of vegetation in the dynamics of West African Monsoons. J Clim 11:2078-2096 